University of Louisville

ThinkIR: The University of Louisville's Institutional Repository

Electronic Theses and Dissertations

8-2015

\title{
Temporal information processing across primary visual cortical layers in normal and red light reared tree shrews.
}

Wenhao Dang

University of Louisville

Follow this and additional works at: https://ir.library.louisville.edu/etd

Part of the Experimental Analysis of Behavior Commons

\section{Recommended Citation}

Dang, Wenhao, "Temporal information processing across primary visual cortical layers in normal and red light reared tree shrews." (2015). Electronic Theses and Dissertations. Paper 2259.

https://doi.org/10.18297/etd/2259

This Doctoral Dissertation is brought to you for free and open access by ThinkIR: The University of Louisville's Institutional Repository. It has been accepted for inclusion in Electronic Theses and Dissertations by an authorized administrator of ThinkIR: The University of Louisville's Institutional Repository. This title appears here courtesy of the author, who has retained all other copyrights. For more information, please contact thinkir@louisville.edu. 
TEMPORAL INFORMATION PROCESSING ACROSS PRIMARY VISUAL CORTICAL LAYERS IN NORMAL AND RED LIGHT REARED TREE SHREWS

\author{
By \\ Wenhao Dang \\ B.S., China Agricultural University, 2009 \\ M.S., University of Louisville, 2013

\begin{abstract}
A Dissertation
Submitted to the Faculty of the

College of Arts and Sciences of the University of Louisville

in Partial Fulfillment of the Requirements

for the Degree of
\end{abstract}

Doctor of Philosophy in Experimental Psychology

Department of Psychological and Brain Sciences

University of Louisville

Louisville, Kentucky

August 2015 

TEMPORAL INFORMATION PROCESSING ACROSS PRIMARY VISUAL CORTICAL LAYERS IN NORMAL AND RED LIGHT REARED TREE SHREWS

By

Wenhao Dang

B.A., China Agricultural University, 2009

M.S., University of Louisville, 2013

A Dissertation Approved on

August 5, 2015

by the following Dissertation Committee:

Dr. Heywood Petry

Dr. Christian Stilp

Dr. Martha Bickford

Dr. Paul DeMarco

Dr. Pavel Zahorik 


\section{ACKNOWLEDGMENTS}

I would like to express my sincere gratitude to my mentor, Dr. Heywood M. Petry, for his continuous support of my study and research. I would also like to thank the other committee members, Dr. Martha Bickford, Dr. Paul DeMarco, Dr. Pavel Zahorik and Dr. Christian Stilp, for their guidance and help over the past five years. I would also like to thank my fellow labmates, Philip S. Marie, Dr. Jon Day-Brown and Dr. Sean Masterson, for the sleepless nights we were working together, and for all the fun we have had in the past five years. Last but not least, I would like to thank my family for supporting me spiritually throughout writing this thesis and my life in general. 


\begin{abstract}
TEMPORAL INFORMATION PROCESSING ACROSS PRIMARY VISUAL CORTICAL LAYERS IN NORMAL AND RED LIGHT REARED TREE SHREWS

Wenhao Dang
\end{abstract}

August 5, 2015

Visual neuroscience research has benefitted from decades of efforts of comparative studies of different species, since exploring and understanding the diversity of functional properties of visual system in different species has helped us identify both general organization rules and unique traits of certain species. In this study, spatio-temporal receptive fields (STRFs), together with some other functional properties (etc. stimulus preference to different visual stimuli, orientation tuning, temporal frequency tuning and the F1/F0 ratio of responses to sine-wave grating stimuli), of primary visual cortex (V1) cells were measured in normally reared and red-light reared tree shrews (Tupaia), a species considered the closest non-primate relative to human being. All data were sampled in anesthetized animals using extracellular recording techniques. In the current study, a diversity of STRFs structures were found in tree shrew V1, and the STRFs found were classified into two categories, Type I receptive fields (RFs) that had spatially discontinuous on- and off-regions, or had spatio-temporal inseparable RFs, and Type II RFs that had spatially overlapped circular or elliptical on- and off- regions, and spatio-temporal separable RFs. Spatial and temporal profile analysis indicated this Type I and Type II 
classification did not correspond to simple and complex RF types previously described in primates and carnivores. It was also found in the current study that the linear prediction based on STRFs did not predict temporal frequency tuning, orientation tuning or the F1/F0 ratio very well in tree shrew V1. In tree shrew V1, both low-pass and band-pass cells for temporal frequency were found, and the proportion of cells with different types of tuning curves also differed across layers, resulting in a low-pass filter between layer II/II and layer IV. Last but not least, it was found in this study that red light rearing after birth changes the population stimulus preference in layer IV in tree shrew V1. 


\section{TABLE OF CONTENTS}

ACKNOWLEDGMENTS




\section{LIST OF FIGURES}

FIGURE

PAGE

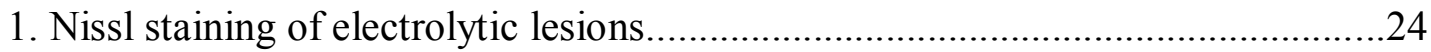

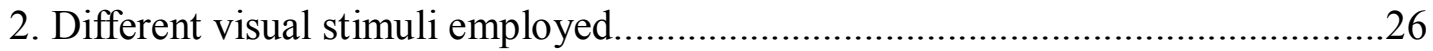

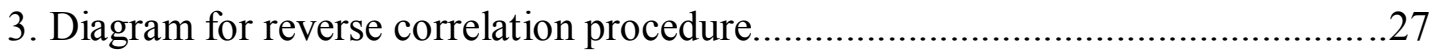

4. Representative neuron responses to different stimuli............................................33

5. Representative spatial and temporal structure of Type I and Type II receptive fields

6. Distribution of temporal interval between on- and off- peaks for Type I RFs.........36

7. Distribution of temporal interval between on- and off- peaks for Type II RFs.......37

8. Distribution of spatial overlap index and aspect ratio for type II RFs...................39

9. Lamina profile of stimulus preference in normally reared animals......................41

10.Lamina profile of stimulus preference in red light reared (RLR) animals............42

11. Scatter plot of stimuli preference and orientation tuning index...........................43

12. Stimuli preference of cells with different RF structures in normally reared animals

13. Stimuli preference of cells with different RF structures in RLR animals. .45

14. Lamina organization of $\mathrm{F} 1 / \mathrm{F} 0$ ration. 47

15. Scatter plot of "on off balance index" and F1/F0 ratio . .48

16. Both temporal frequency low-pass and band-pass cells exist in tree shrew primary 
visual cortex

17. Low-pass filter between V1 layer II/III and layer IV.

.51

18. Discrepancy between measured temporal frequency tuning curve and linear model

predicted curve.

.53

19. Lamina profile of orientation tuning and performance of linear prediction........55 


\section{INTRODUCTION}

General

Tree shrews (Tupaia) are small squirrel-like animals native to southeast Asia. They are considered prototypes of early prosimian primates, and thus have received extensive study as a model for the evolution of primates. Tree shrews are diurnal, arboreal mammals with fast and agile movements. This living style indicates that tree shrews possess well-developed temporal vision. Electroretinographic (ERG) studies (Tigges, Brooks, \& Klee, 1967) have revealed a critical flicker frequency (CFF) of $75 \mathrm{~Hz}$ or more, which is higher than that of humans $(50-60 \mathrm{~Hz}$; de Lange, 1954). Temporal modulation sensitivity functions (tMSFs) also showed a higher peak frequency in tree shrews $(15 \mathrm{~Hz})$ than in human $(10 \mathrm{~Hz})$ (Callahan \& Petry, 2000).

Together with squirrels and some new world primates, tree shrews are one of the only mammalian groups with established cone-dominant retinas, and it has been conjectured that cone-dominant retinas might be an adaptation for better motion detection (Ahnelt \& Kolb, 2000). Tree shrew color vision is characterized by a spectral neutral point at $505 \mathrm{~nm}$ due to their retina containing only two types of cones: long-wave-sensitive (LWS) cones (sensitivity peak around 560nm) and short-wave-sensitive (SWS) cones (sensitivity peak around 440nm), and only 5\% rods (Jacobs \& Neitz, 1986; Müller \& Peichl, 1989; Petry \& Harosi, 1990). Similar to the 
$\mathrm{X}$ and Y retinal ganglion cells (RGCs) in cat (Cleland, Dubin, \& Levick, 1971; Enroth-Cugell \& Robson, 1966) and other species, a transient/sustained dichotomy was also found in the tree shrew retina (Dongen, ter Laak, Thijssen, \& Vendrik, 1976; Thijssen, van Dongen, \& ter Laak, 1976). Sustained-type neurons are slow to adapt and respond continuously following the onset or offset of light, while transient-type neurons respond briskly to the onset and/or offset of the light and show rapid adaptation. When stimulated with a temporally modulated Gaussian spot, the sustained cells had lower peak frequencies and high-cutoff frequencies. Electrophysiological recordings made in the optic tract of tree shrews revealed that cells with sustained and transient response properties each comprise about one third of the RGCs, the other third exhibited response properties ascribed to W-like cells such as selective to movement direction, large center diameter, low spike density etc. (Lu \&Petry, 2003).

Like primates, the dorsal lateral geniculate nucleus (dLGN) of the tree shrew consists of six well-defined cellular lamina separated by cell-sparse inter-laminar zones. However the functional organization of the six laminais a little different from primates (Holdefer \& Norton, 1995). Whereas in primates, tonic-firing parvocellular and phasic-firing magnocellular cells are separated in different layers (Derrington \& Lennie, 1984; Merigan \& Maunsell, 1993), in the tree shrew, cells with tonic and phasic temporal characteristics are intermixed in each layer, and the layers are organized by on- and off-center response preferences as well as by ocular input. 
Lamina 1 and 5 receive input only from the ipsilateral eye; while lamina 2,3,4,6 receive projections from the contralateral eye. Almost all neurons in lamina 1 and 2 respond predominantly to the onset of the stimulus (on-cells), while neurons in lamina 4 and 5 respond predominantly to the offset of the stimulus (off-cells). Lamina 3 contains a mixture of on- and off center cells; and lamina 6 and the inter-laminar zone are mostly on-off center cells (Holdefer \& Norton, 1995).

This segregation of the on and off channels is maintained at the cortical level by an orderly projection from the dLGN to V1 in the tree shrew (Casagrande \& Harting, 1975; Conley, Fitzpatrick, \& Diamond, 1984, Van Hooser, Rhodes, Culp \& Fitzpatrick, 2013). Layer IVa is innervated by terminals from dLGNlaminal and 2, while dLGN lamina 4 and 5 project predominantly to cortical layer IVB. The dLGN lamina 3 and 6 appear to have principal targets that differ from those of the other dLGN lamina. Lamina 3 projects to cortical layer IIIb and to more superficial layers, and lamina 6 projects to a thin strip at the top of layer IVa. Physiological properties of V1 cells are in good accordance with this projection pattern. Cells in layer IVa are mostly on-cells, cells in layer IVb are off-cells, and cells in superficial and deep layers are predominantly on-off cells (Norton, Rager, \& Kretz, 1985). In addition to this laminar organization, orientation selectivity is found to vary horizontally across the tree shrew V1 (Humphrey, Skeen, \& Norton, 1980).But different from cat and primates, whose orientation map in V1 have pinwheel-like patterns (Bonhoeffer \&Grinvald, 1991; Blasdel, 1992), orientation preference map in tree shrew show 
parallel stripes pattern around the border of $\mathrm{V} 1$, and more punctate set of domains in the center (Bosking, Zhang, Schofield \& Fitzpatrick, 1997).

The properties of a higher order cortex that processes temporal or motion information is not very clear in the tree shrew. A temporal dorsal area (TD) has been hypothesized to be the homologue of primate middle temporal (MT) cortex because it shares some anatomical features. For example both TD and MT receive dense inputs from both V1 and V2, and the axons are heavily myelinated (Glenn Northcutt \& Kaas, 1995; Jain, Preuss, \& Kaas, 1994; Kaas \& Preuss, 1993; Sesma, Casagrande, \& Kaas, 1984). It was known that cells in this region were responsive to visual stimuli, but the receptive fields were large and difficult to delineate (Kaas, Hall, Killackey, \& Diamond, 1972; Kaufmann \& Somjen, 1979). No further attempts have been reported to search for its best driving stimuli, tuning properties and receptive field structure.

STRFs and laminar profiles

Vision, like other sensory modalities, emerged in evolution to help animals survive, and it does that by precisely and flexibly guiding animals' behavior to adapt the surrounding environment. With that being said, it is easy to understand the concept of "feature detection", in which the visual system is viewed as a "feature detector" rather than a film and camera that precisely "projects" the physical world pixel to pixel (Martin, 1994). Because the information contained in this complex 
world is so overwhelming for an energy efficient system, the better idea is probably just to extract a series of features that are most relevant to animals' survival. This "feature detector" theory, probably the most widely accepted model of what single neurons do in visual system, had been supported by much experimental evidence in different animal models, as well as at different stages in visual processing. The first evidence comes from the "bug detector" cells in toad retina (Barlow, 1953). These neurons responded to small object moving across their receptive fields (RFs), but not to overall luminance change or to moving edges. Similarly, oriented contrast edge detectors were found in mammalian primary visual cortex, and cells that are selective to more complex shapes, moving directions, and even faces were also found in higher hierarchy stages in visual processing (Albright, 1984; Hubel \& Wiesel, 1962; Sereno \& Maunsell, 1998; Tanaka, 1996).

Since all visual features can be viewed as specific combinations of certain spatial and/or temporal patterns, it was first proposed in theory and later confirmed by numerous empirical studies that the feature detection ability of visual neurons can be predicted from the spatial and/or temporal structure of their receptive field (RF). These efforts to characterize the RF structure of visual neurons led to a greatly deepened understanding of visual computation, like direction and speed tuning, as well as degree of linearity to grating stimuli (Baker, 2001; Dean \& Tolhurst, 1983; Gardner, Anzai, Ohzawa, \& Freeman, 1999; Hubel \& Wiesel, 1959; Kagan, Gur, \& Snodderly, 2002; McLean \& Palmer, 1989; Reid, Soodak, \& Shapley, 1988; Yeh, 
Xing, Williams, \& Shapley, 2009). Since orientation selectivity is the most prominent, and a new emerging feature in cortical cells' RFs compared to their thalamic input, most early studies of cortical RF structure focused on this property. Efforts were made to answer the question of how much of the cell's orientation selectivity can be accounted for by its first order spatial receptive field map in primary visual cortex. When Hubel and Wiesel (1959) first found orientation selectivity in cat primary visual cortex, they also mapped the spatial structure of those cells' RFs. This led to the discovery that some of the cells have non-overlapping, elongated RF sub-regions that can be activated by opposite contrast (i.e., sub-regions activated by luminance increment were called the on-region, by luminance decrement termed the off-region). They named those cells "simple cells". The preferred orientation of simple cells is almost always parallel to the long axes of the cell's side-by-side elongated on-and off-sub-regions, and their response to grating were modulated by the phase of stimuli (high F1/F0 ratio, where F0 is cell's the average firing rate to its preferred grating stimuli, and F1 is the modulation depth of cell's firing rate to its preferred grating). This was in good accordance with the prediction of a linear model, since for approximately half of the grating cycle, the polarity and orientation of stimuli matched that of RF, maximizing the activation of the cell, while in the other half cycle the activation was much less. Complex cells, on the other hand, had mostly overlapping on- and off- sub regions, and low F1/F0 ratio to grating stimuli. Their response cannot be predicted with a single linear filter, since even at the same location within the RF, both contrast polarities can activate the cell, making the cell insensitive 
to the phase of the grating (i.e. low F1/F0 ratio). Later studies also showed that this first order map can offer a decent prediction for the spatial frequency preference for most simple cells (Dean \& Tolhurst, 1983; Kagan et al., 2002; Veit, Bhattacharyya, Kretz, \& Rainer, 2013). These findings suggested the simple cells mostly operate in a linear fashion when processing simple sine-wave grating stimuli, and this observation had an important implication for understanding the processing of more complex visual stimuli, since the Fourier theorem states that any periodic function can be expressed as the sum of a series of sine or cosine terms. Previous adaptation experiments (Blakemore \& Campbell, 1969) showed the existence of multiple channels for different sine wave gratings in the human visual system.

Mapping of RFs also helped to refine the model of how feature selectivity is formed. Based on the difference between observed RF structures in V1 and LGN, Hubel and Wiesel (1959) developed the feed-forward model of orientation selectivity for cortical cells. Specifically, they proposed that simple cells are constructed from spatially-aligned LGN input with the same contrast polarity preference, and complex cells are formed by feed-forward input from simple cells having the same orientation preference and slightly different spatial locations. Both the pros and the cons for this theory derive largely from investigations on RF structures. Several studies confirmed that the monosynaptic connectivity probability is highest when both location and polarity match in cortex and LGN neurons, confirming the structural basis for feed-forward model (Alonso, Usrey, \& Reid, 2001; Chung \& Ferster, 1998; Ferster, 
Chung, \& Wheat, 1996; Reid \& Alonso, 1995; Tanaka, 1983; Usrey, Alonso, \& Reid, 2000). However other, more recent studies have reported phenomenon that cannot be explained alone by a feed-forward model. One study showed that although the preferred orientation can be well predicted from the first-order RF map, the sharpness of tuning is always underestimated (Gardner, Anzai, Ohzawa \& Freeman, 1999). Another study found progressively sharper orientation tuning at a time scale slower than what was predicted by a feed-forward mechanism (Shapley, Hawken, \& Ringach, 2003), thus leading to new areas of research on intra-cortical nonlinear mechanisms of orientation tuning, such as spike threshold, differential inhibition and recurrent excitatory amplification (Adorján, Levitt, Lund, \& Obermayer, 1999; Ferster, 1988; Ferster \& Miller, 2000; Hirsch et al., 2003; Monier, Chavane, Baudot, Graham, \& Frégnac, 2003; Priebe \& Ferster, 2005, 2012; Priebe, Mechler, Carandini, \& Ferster, 2004).

To completely characterize the first-order kernel of cells, the temporal aspect of the RF is also required. The best known and pioneering study on this issue was that of Jones and Palmer (1987). They used sparse noise and a reverse correlation method to construct a complete spatial-temporal map. In many subsequent reverse correlation studies, different visual stimuli, such as m-sequence noise or gratings with random spatial and orientation parameters, were also used for various purposes (Conway \& Livingstone, 2003; Dean \& Tolhurst, 1983; Gardner et al., 1999; Ringach, 2004; Sedigh-Sarvestani, Fernandez-Lamo, Jaegle, \& Taylor, 2014; Touryan, Felsen, 
\& Dan, 2005; Yeh et al., 2009). The general rule of reverse correlation is the same: correlating spikes with visual stimuli at varied times preceding the spike. This extension into the time domain enabled researchers to test linear models that not only predicted how cells respond to spatial information, like orientation or spatial frequency, but also to temporal information like motion direction, temporal frequency and speed (McLean \&Palmer, 1989; McLean, Raab, \& Palmer, 1994; Reid et al., 1988). A good example of this kind of study is the confirmation of inseparable RFs predicted by the spatial-temporal energy model for motion (Adelson \& Bergen, 1985). In the spatial-temporal energy model, neurons are proposed to be oriented spatial and temporal linear filters. This model also proposed that the "joint STRFs" (spatial-temporal RFs) of some neurons are simply the product of their spatial and temporal maps, termed separable RFs. In contrast, some cells' STRFs cannot be expressed as a simple product, and are termed inseparable RFs. For separable RFs the "blobs" in the map, representing contrast polarity preferences across space and time in the joint spatial-temporal map (X-T map), do not shift position in space, while for inseparable RFs the "blobs" are tilted in X-T map. The spatial-temporal energy model predicts that the cells with separable RFs are good motion detectors but are not directionally selective, while those with inseparable RFs are directionally selective, with the tilted orientation of "blobs" indicating the preferred direction. These predictions largely have been confirmed by experimental data (McLean \& Palmer, 1989; Reid, Soodack \& Shapley,1987).For example, predictions based on spatial-temporal characteristics capture the orientation preference of V1 cells fairly 
well. However, another fact is that the linear model seems to overestimate the tuning width of orientation tuning, indicating that nonlinear mechanisms can still play an important role in V1 (Gardner et al., 1999).

The complexity of neuro-computation not only lies in dynamics but also in the diversity of RFs of individual cells. There are multiple parallel pathways in the visual system, and in each pathway, there are multiple hierarchies extracting different features. For example in primates, there are at least three parallel pathways (e.g., the $\mathrm{P}$ (parvocellular), M (magnocellular) and $\mathrm{K}$ (koniocellular) pathways), with distinct anatomical and physiological features (Livingstone \& Hubel, 1988). The segregation of these pathways begins at the first visual synapse, and is maintained at the cortical level in the classical model. To be specific, in the retina, parvocellular projecting $(\mathrm{P})$ midget retinal ganglion cells (those projecting to ventral dorsal 4 layers in LGN of primates) receive their inputs from midget bipolar cells, which receive input from a single cone in the central visual field. On the other hand magnocellular projecting $(\mathrm{M})$ parasol retinal ganglion cells (those projecting to the ventral 2 layers in LGN of primates) are innervated by diffuse bipolar cells, which in turn sample from several rods and cones (Leventhal, Rodieck \& Dreher, 1981; Perry, Oehler \& Cowey, 1984, Bowling \& Michael, 1980; Sherman \& Guillery, 1996). When information is sent from the LGN to the primary visual cortex, magnocellular cells synapse in layer IVC $\alpha$ then project to layer IVB, and parvocellular cells synapse in IVC $\beta$ then to IVA and layer II/III (Gilbert \& Kelly, 1975). From the perspective of physiological 
properties, cells in the P pathway show spectral opponency/selectivity, low luminance contrast gain, smaller receptive field size and poor contrast sensitivity at scotopic luminance. In contrast, $\mathrm{M}$ pathways generally have no color opponency, higher luminance contrast gain, larger receptive field size and good contrast sensitivity at scotopic luminance. Consequently these two pathways in monkey were also called the color/form and the luminance/motion pathways respectively (Kaplan, Lee, \& Shapley, 1990; Lee, 1996; Merigan \& Maunsell, 1993). Pathways in humans characterized psychophysically, and presumably based on similar neural mechanisms, have been termed color-opponent and luminance channels (e.g., King-Smith \& Carden, 1976).

Some key physiological features of cortical cells are known to change with laminar location. In the monkey primary visual cortex (V1), it is known that simple cells, which have spatially separated on-off RFs and high orientation selectivity, are preferentially located in the magnocellular pathway dominated layers (IVC $\alpha$ and upper tier of layer VI), while complex cells usually exhibit less orientation selectivity and are located mostly in the superficial and deep layers. Very similarly, in cats cells with simple RFs are found mostly in direct thalamo-recipient zones, while complex cells are found in all layers other than layer IV (Hirsch \& Martinez, 2006b). Some investigations on laminar differences of linearity were also conducted, inspired by the fact that different layers are in different hierarchies of information flow. Since, in general, visual information travels from layer IV to layer II/III, and finally to layer V 
in primary visual cortex (Douglas \& Martin, 2004; Gilbert, 1983), one would expect differences across layers. In both monkey and cat, the proportion of simple cells, as well as the spatial segregation of RF sub-regions, tends to decline with distance from direct thalamic input (Boyd \& Matsubara, 1996; Hirsch \& Martinez, 2006a; Hubel \& Wiesel, 1968). In a recent study, in-vivo whole cell recording was used in the cat cortex to reveal the "Push-Pull" structure of STRFs (Martinez et al., 2005) (Here "Push" means excitation and "Pull" means inhibition). It was found that the segregated RFs in layer IV mostly have "Push-Pull" structure, meaning that at the same location and at the same time delay after a visual stimuli, the cell will get opposite input to opposite contrast polarity (for example, in an on- subregion, luminance increscent causes excitatory input, while luminance decrement results in inhibitory input). However complex RFs in other layers were found mostly to have "Push-Push" structure. Through intracellular recording, it was also revealed that the interaction between excitation and inhibition underlying orientation selectivity changed across layers (Martinez, Alonso, Reid, \& Hirsch, 2002). Finally, different layers display different oscillations in local field potential, indicating different network structure and dynamics (Sun \& Dan, 2009).

In a few recent studies, the laminar profile of RFs in the tree shrew visual system were measured. Van Hooser and colleagues (2013) recorded responses from tree shrew dLGN, layer IV and II/III of primary visual cortex. A moving bar was used to roughly measure the degree of spatial overlap of on- and off- sub-regions 
based on the time difference of response to an on-and off- flashing bar stimuli. Grating stimuli were used to test orientation tuning, temporal frequency tuning, as well as modulation depth (simple cells vs. complex cells). They found that compared to neurons in the dLGN and the cortical layer IV, those in layer II/III had slightly higher ON/OFF segregation and a larger proportion of complex cells. They also found that unlike cats, sharp orientation tuning properties emerged in layer II/III of V1 in the tree shrew, rather than in layer IV. In addition, a big decrease in the neuron's preferred temporal frequency between LGN cells and layer IV in V1 was also found. The authors suggested that, in contrast to cats, many response property transformations in the tree shrew visual system happen within the cortical circuits. Veit and colleagues (2014) applying a more "standard" approach, used sparse noise stimuli to map the on- and off- sub-regions of V1 cells in the tree shrew. With a different overlapping index that is not directly comparable to that used by Van Hooser et al (2013), they revealed that most cells in tree shrew V1 have largely overlapping sub-fields irrespective of laminar location. Higher degrees of orientation tuning in response to drifting sine-wave gratings were also found in this study, but no difference in the complex/simple cell ratio was observed between layer II/III and layer IV.

Mapping the full STRFs at different stages of visual system can greatly help us refine our understanding of how the brain performs feature extraction, but so far this approach has been mostly used to analyze the spatial domain, particularly orientation coding. Very few efforts have been made to specifically dissect temporal 
processing with STRFs (Dean \& Tolhurst, 1983; McLean \& Palmer, 1989; Párraga, Troscianko, \& Tolhurst, 2005; Reid et al., 1988). The current project addressed this by recording responses from different layers of tree shrew primary visual cortex in response to a variety of temporal visual stimuli, including flashing spots, drifting sine-wave gratings, and coherent random dots kinematograms (RDKs). We employed reverse correlation methods to map the full first-order kernels of recorded neurons. The benefits of using different stimuli was to provide the opportunity to observe how cells respond to different combinations of visual features. For example, a flashing spot only contains localized contrast temporal modulation; drifting gratings have orientation, moving direction and spatial frequency; and RDKs represent relatively pure "motion", since the circular shape of the dots is devoid of all orientation, and sharp edges contain wide range of spatial frequencies.

First-order STRFs had been used to predict responses to various classical visual stimuli in V1. In the spatial aspect it was found that spatial frequency, F1/F0 ratio, and some aspects orientation selectivity can be predicted fairly well for cells with separated on-off sub-regions in cat and monkey; However, higher order interactions need to be considered to give a decent prediction for complex cell dominant layers. In the temporal domain, the spatial-temporal energy model has also been used to predict neurons' activity to RDKs at various speed. Previously it was found that for the same cell, the direction preference can change when dot speed changed, and direction preferences at high and low speed are usually 
orthogonal(Geisler, Albrecht, Crane, \& Stern, 2001; Jancke, 2000). It was proposed that this phenomenon is caused by "temporal smear" in STRFs, in which case the cell is activated by temporal energy (moving) at low speed, and by a more "static moving axis" at high speed. Particularly interesting is that the spatial temporal model can precisely predict the "critical speed" at which the transition happens (An, Gong, McLoughlin, Yang, \& Wang, 2014).

Our model system, the tree shrew, is an especially interesting model to study laminar profiles of temporal processing and STRFs, firstly, because tree shrews have superior temporal vision and a more primate-like visual system compared to carnivorous animal models like cats and ferrets, and secondly that they may have different mechanisms compared to primate and cats in forming some of the feature extraction properties in visual cortex, for example, dominant simple cell like response with highly overlapped on- and off- subregions in V1cells.Another example is that orientation selectivity emerges in layer II/III in tree shrew primary visual cortex rather in layer IV in cat. It has been reported that intracortical feed-forward as well as horizontal connection mechanism play important roles in forming the orientation selectivity in tree shrew V1. In the tree shrew, the axonal projection from orientation non-selective layer IV cells to orientation selective layer II/III cells is biased, specifically, by axons of layer IV cellspreferentially targeting layer II/III sites whose orientation preference matches the axis of visual field displacement between the presynaptic and postsynaptic cells. At the same time, horizontal connections within 
layer II/III are also biased to sharpen the orientation tuning: cells with similar orientation preference are more strongly linked by horizontal connections. (Bosking, Zhang, Schofield, \& Fitzpatrick, 1997; Chisum, Mooser, \& Fitzpatrick, 2003; Mooser, Bosking, \& Fitzpatrick, 2004; Van Hooser, Roy, Rhodes, Culp, \& Fitzpatrick, 2013; Veit et al., 2013).Studying the tree shrew will help us better understand diversity versus homogeneity in visual processing.

\section{RLR experiments}

It had been found in many species that visual experience plays an important role during early postnatal life in shaping the visual system, and abnormal visual stimulation during development has a profound effect on the visual neuron properties and visual system organizations (Sherman \& Spar,1982; Boothe, Dobson \&Teller, 1985). Very interestingly, monocular deprivation resulted in more severe impairments than binocular deprivations (Wiesel \& Hubel, 1965). The mechanism underlying this result is thought to be the result of abnormal competition between the cells driven by deprived eye and cells driven by normally stimulated eye. However, if this competition interaction also occurs among other physiologically, anatomically and psychophysically identified visual pathways (e.g. W, X and Y pathways: Hoffmann, Stone \& Sherman, 1972; M and P pathways: Livingstone \& Hubel, 1988; color-opponent and luminance pathways: King-Smith \& Carden, 1976) is not clear. this is because a prolonged differential stimulation of selected channels is a difficult condition to achieve during development. 
In our lab, we have been able to differentially stimulate the color-opponent and luminance channels during early postnatal development by utilizing tree shrew animal model and red light rearing (RLR) paradigm. In RLR paradigm, tree shrew pups were reared in deep red light environment for 8 weeks. Because tree shrews have a cone dominant retina and only two types of cones, this red light rearing will deprive all external stimulation of SWS cones, while stimulate LWS cones relatively normally. Like monkey and human, SWS cones also appear to contribute little to the luminance channel in this species (Eisner \& Macleod, 1980; Petry, 1993). Thus the red light rearing paradigm would be expected to create a competitive advantage for the luminance channel over the color-opponent channel. Since the luminance channel was thought to contribute more to higher temporal frequency vision, this biased competition may result in an enhancement in neural response and possibly also in behavior to higher temporal frequency visual stimuli. Works by Petry and colleagues have shown this hypothesis likely to be correct. Despite no change in the size of the SWS cone population (Petry, Erichsen \& Szel, 1991), histochemical studies showed the SWS cones in the RLR shrews were lacking nitric oxide synthesis (Murphy \& Petry, 1995), and RLR shrews showed poorer color vision (Petry and Kelly, 1991). These results are consistent with a compromised color-opponent channel that is affected beginning at the retinal level.

In contrast, the "luminance channel" of RLR tree shrews appeared to be 
enhanced. Petry and colleagues (1992) showed enhanced luminance channel mediated spectral sensitivity, and behavioral studies by Callahan and Petry (1995) showed that RLR shrews were able to detect flickering lights at much higher temporal frequencies than normally-reared shrews. This difference was documented physiologically by recordings from retinal ganglion cells (Lu and Petry, 2002) and by calcium imaging of layer II/III neurons in area V1 of normal and RLR shrews (Van Hooser, Johnson \&Petry, 2014). However, it is worth pointing out that what is happening in layer IV and below in RLR shrews is not clear. The change in layer II/III following a developmental deprivation of SWS cones is consistent with the observation that superficial layers of tree shrew V1 receive the main input from dLGN layer III ( Usrey, Muly \& Fitzpatrick, 1992), which is the only layer in the tree shrew LGN that can be driven by a SWS cone isolation stimulus (Johnson, Van Hooser \& Fitzpatrick, 2010). It is also in agreement with the observation that in tree shrew layer II/III, LWS cone isolation stimuli driven cell populations displayed higher temporal frequency cutoffs than SWS cone isolation stimuli driven population (Johnson et al., 2010).

This most recent result in the series of the red-light-rearing studies has implications for the processing of temporal information in the normal visual system, especially for the geniculocortical circuit (e.g., dLGN to V1). It was found previously in tree shrew and other species that cortical cells do not respond well to rapidly changing stimuli compared to LGN cells ( Hawken, Shapley \& Grosof, 1996; Van Hooser et al., 2013). For example, the preferred temporal frequencies of simple 
cells in cats are lower by a factor of 2 compared to LGN cells $(8 \mathrm{~Hz}$ vs. $16 \mathrm{~Hz})$. One element that surely contributes to this "low pass filter" between thalamocortical inputs and V1 outputs is the capacitor property of the V1 cell membrane. With a membrane constant near $15 \mathrm{~ms}$, the frequency at which the membrane filter attenuates its input by a factor of 2 is about $11 \mathrm{~Hz}$. This filter can explain about half of the difference between preferred temporal frequencies of LGN and V1 neurons (Priebe \& Ferster, 2012). One hypothesis to account for the remaining mismatch is that the filtering effect is the result of imperfectly aligned LGN inputs in time. In other words, the varied latencies of LGN input will cause dispersion in postsynaptic activation for V1 cells, and obviously this dispersion will have a bigger effect for high temporal frequencies.

The RLR tree shrews provide us an interesting model to study developmental aspects cortical temporal information processing. In the RLR tree shrew the "low pass filter" appears to be modified and not simply removed. Van Hooser et. al's (2013) imaging study of layer II/III neurons in RLR shrews showed that the grand average of responses not only showed an enhanced response to higher frequencies $(15 \mathrm{~Hz}-20 \mathrm{~Hz})$, but also a small enhancement at low end frequencies $(1 \mathrm{~Hz})$. The changes on two ends of temporal frequency spectrum suggest that that this change may be caused by two mechanisms, or happening on two different cell populations. Thus identifying and categorizing temporal frequency tuning curves as well as STRFs into possible different types, and then charactering the changes in different 
populations may provide more information on the underlying mechanisms of this interesting observation of changes in the vision following red light rearing of tree shrews. 


\section{METHODS}

Animals

36 adult tree shrews (Tupaia belangeri), 17 normally reared and 19 red light reared) with body weight ranging from $120 \mathrm{~g}-180 \mathrm{~g}$ were used in this study. All the animals were colony reared and sexually mature adults ( $>4$ months of age) at the time of recording. The care and treatment of all animals were in strict accordance with $\mathrm{NIH}$ and institutional IACUC guidelines.

Red light rearing

The conditions used by Petry and Kelly (1991) were used as a model to provide a red light rearing environment. A week or more prior to their due date, pregnant tree shrews were moved to a colony room illuminated by deep red light. The red light was provided by tungsten lights filtered with Kodak 1A Safelight filters (600nm cutoff). These lights were mounted directly above each cage resulting in an illuminance range of approximately 110-270 lux, comparable to the intensity to the "white-light" illumination of the main colony room. A revolving "dark-room" type door allowed entry into the room without contaminating the red-light environment. Tree shrew pups were born in the red light and hand-reared in red light until 8 weeks of age, at which time they were transferred to the main colony room. Recordings were conducted when the shrew were adults (i.e., 16-weeks of age or 
older).

Anesthesia and surgery

Tree shrews were initially anesthetized with Ketamine $(100 \mathrm{mg} / \mathrm{kg}$, IM), under which a tracheotomy was performed, and subsequently with nitrous oxide gas anesthesia(70/30 N2O/O2) supplemented with $0.5-2.0 \%$ isoflurane. Following bladder cannulation, tree shrews were moved to a stereotaxic apparatus and a craniotomy was made above V1 for subsequent extracellular recording. Atropine sulfate $(0.2 \mathrm{mg} / \mathrm{kg}, \mathrm{IP})$ was used to prevent salivation and bronchial secretions, and sterile saline solution was continuously infused into abdominal cavity throughout the experiment to prevent dehydration of the animal. Pupils were dilated with atropine sulphate(1\%), and plano contact lenses were used to prevent dehydration of the corneas. Upon discovery of the first recordable neuron, gallaminetriethiodide( $15 \mathrm{mg} / \mathrm{kg}$, IM) was injected to eliminate eye movements, and artificial respiration was begun (60 bpm). Core temperature was maintained between 37-38 degrees Celsius. The electro-cardiogram and expired $\mathrm{CO} 2 \%$ were continuously monitored and computer-controlled alerts were set to predetermined thresholds and used to monitor significant deviations.

\section{Extracellular recording}

Tungsten microelectrodes with $0.5-2.0 \mathrm{M} \Omega$ impedance at $1000 \mathrm{~Hz}$ were used. The raw neuronal signal was first amplified and band-pass filtered $(300-3000 \mathrm{~Hz})$ using an HI4 head stage and DB4 amplifier (World Precision Instruments Inc.), then 
the signal was fed into a Power 1401 data acquisition interface (Cambridge Electronics Design Inc., U.K.) for ADC sampling. Spike events were detected by a threshold manually set by the experimenter. All spike events were sampled at $20 \mathrm{kHz}$. Spike 2 data acquisition software (Cambridge Electronic Design Limited, UK) was used for neural recording and spike sorting. A template-matching algorithm was used in the software to isolate single unit activity. That is, every spike was compared to a template waveform, which was the average waveform of spikes previously assigned to the template. If more than a certain percentage of points in an unsorted spike waveform fell within a predetermined range of the template, the spike was assigned to the matched template. Sorting parameters were varied to maximize the isolation of template clusters in PCA (Principal Component Analysis) plots. Electrolytic lesions $(15 \mathrm{uA}, 10 \mathrm{sec})$ were made at cell locations after each penetration for recording sites reconstruction. A typical lesion is shown in Figure 1.

\section{Histological processing}

At the completion of each experiment, the animal was perfused through the heart with $0.9 \%$ saline followed by $4 \%$ paraformaldehyde. Prior to extraction, the brain was blocked in the coronal plane parallel to the electrode penetration. Brains were then stored in $4 \%$ paraformaldehyde as post-fixation procedure. In most cases, a special medium (gelatin/albumin/glutaraldehyde) was used to encase the brain during vibratome cutting(Other brains were cut frozen with cryostat).Serial sections of 50 $\mu \mathrm{m}$ were mounted on slides and stained using a standard Nissl staining protocol. 


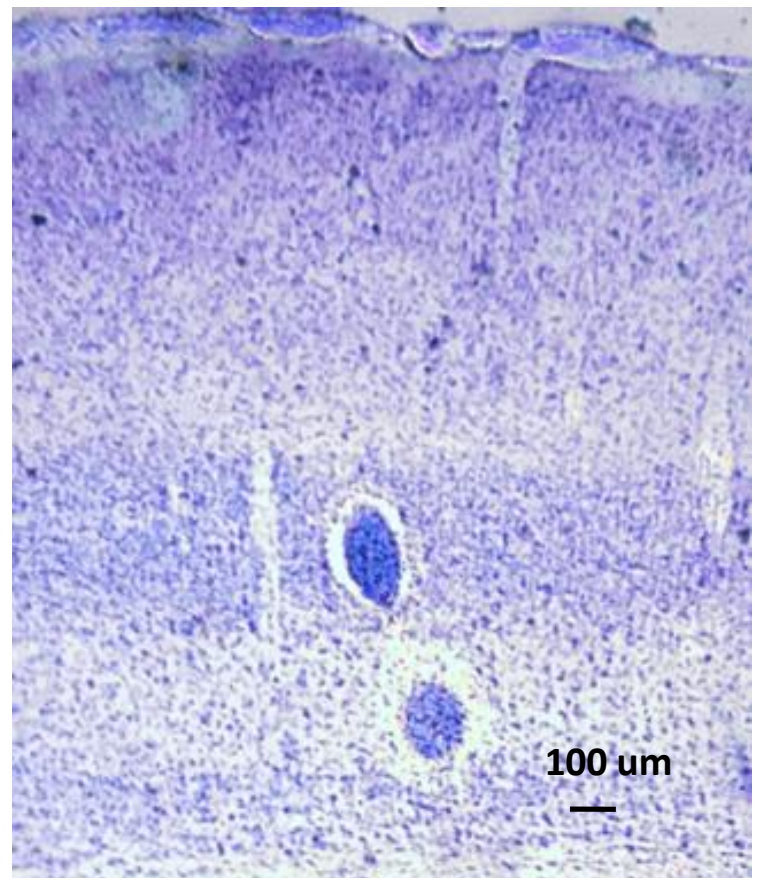

Figure 1. Two electrolytic lesions $(15 \mu \mathrm{A} \times 10 \mathrm{sec})$ in layer IV and $\mathrm{V}$ in a Nissl-stained section of tree shrew visual cortex). 
Sections were then examined for the presence of lesions and electrode tracts using a bright field microscope. The locations of recorded cells were then determined using the lamina position of the lesion centers. Normalized depth was calculated by dividing the distance between the cortical surface to lesion centers by the distance between cortical surface to the bottom of layer VI.

Visual stimuli

All visual stimuli were generated using MATLAB PsychToolboxon a39 $\mathrm{cm} \times 22 \mathrm{cmcolor}$ CRT monitor (set to $120 \mathrm{~Hz}$ refresh rate, $1600 \times 900$ resulotion) placed $30 \mathrm{~cm}$ in front of the animal. All stimuli were presented binocularly. A battery of tests was conducted on each cell encountered as described in Figures 2 and 3. First, the temporal frequency tuning was tested using Gaussian flash stimuli. The contrast of the Gaussian spot was square-wave modulated (0-100\%) with equal on and off durations, and the size of the stimuli was approximately 1.5 times the size of CRF (classical receptive field) of the cell under testing. The following frequencies were used: $1 \mathrm{~Hz}, 3 \mathrm{~Hz}, 10 \mathrm{~Hz}, 15 \mathrm{~Hz}, 20 \mathrm{~Hz}, 30 \mathrm{~Hz}$, and $60 \mathrm{~Hz}$. Every frequency was presented for 3 seconds for three times in random order. Each presentation was separated by 5seconds of blank screen (on-cells had a dark inter-stimuli blank screen, off-cells had a bright inter-stimuli blank screen, on-off cells had a gray inter stimuli blank screen). Then, direction selectivity tuning and temporal frequency tuning for drifting sine-wave gratings were measured. In both tests, the grating patch was $100 \%$ contrast and 1.5 times the size of CRF. In the direction test, spatial frequency was optimized, and a presentation rate of $4 \mathrm{~Hz}$ or $8 \mathrm{~Hz}$ temporal frequency was used depending on the 
A.

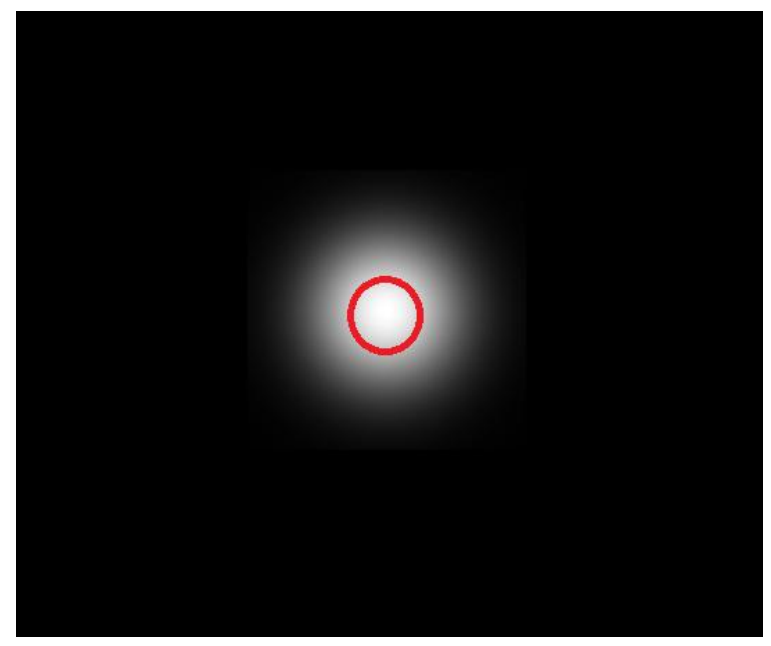

B.

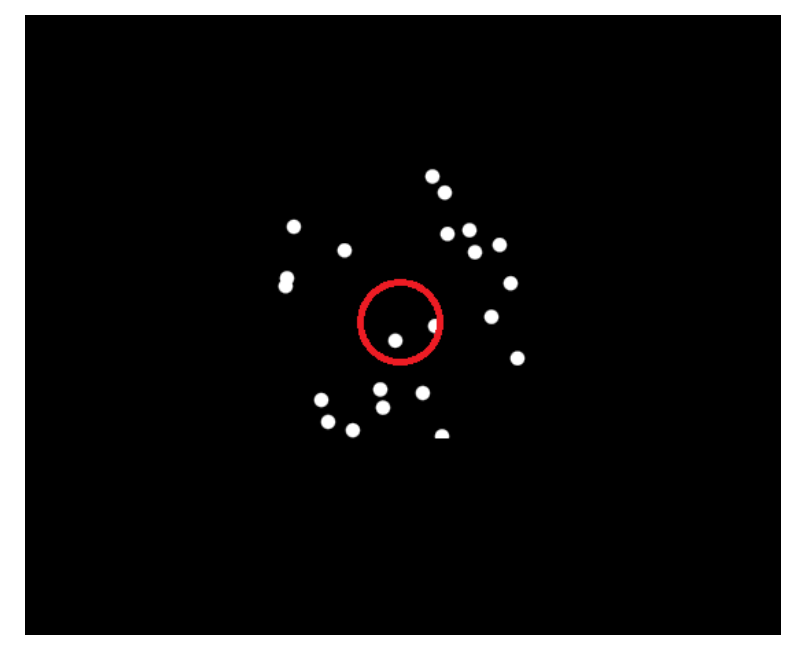

C.

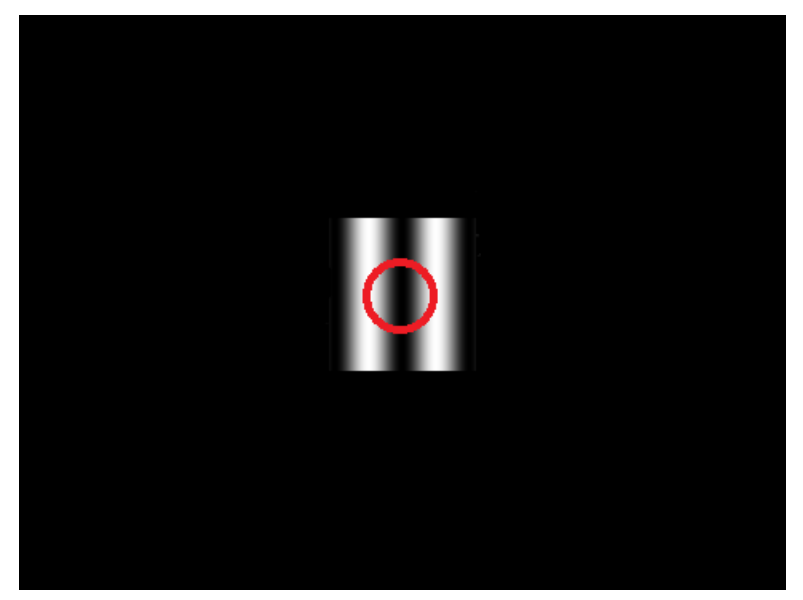

Figure 2.Different visual stimuli were used in the experiments. A.)Gaussian flashing spot stimulus. B.) Random Dot Kinematogram (RDK) stimulus. C.) Drifting sine-wave grating stimulus. The red circle represents the general size and location of the cell's classical receptive field under testing. 

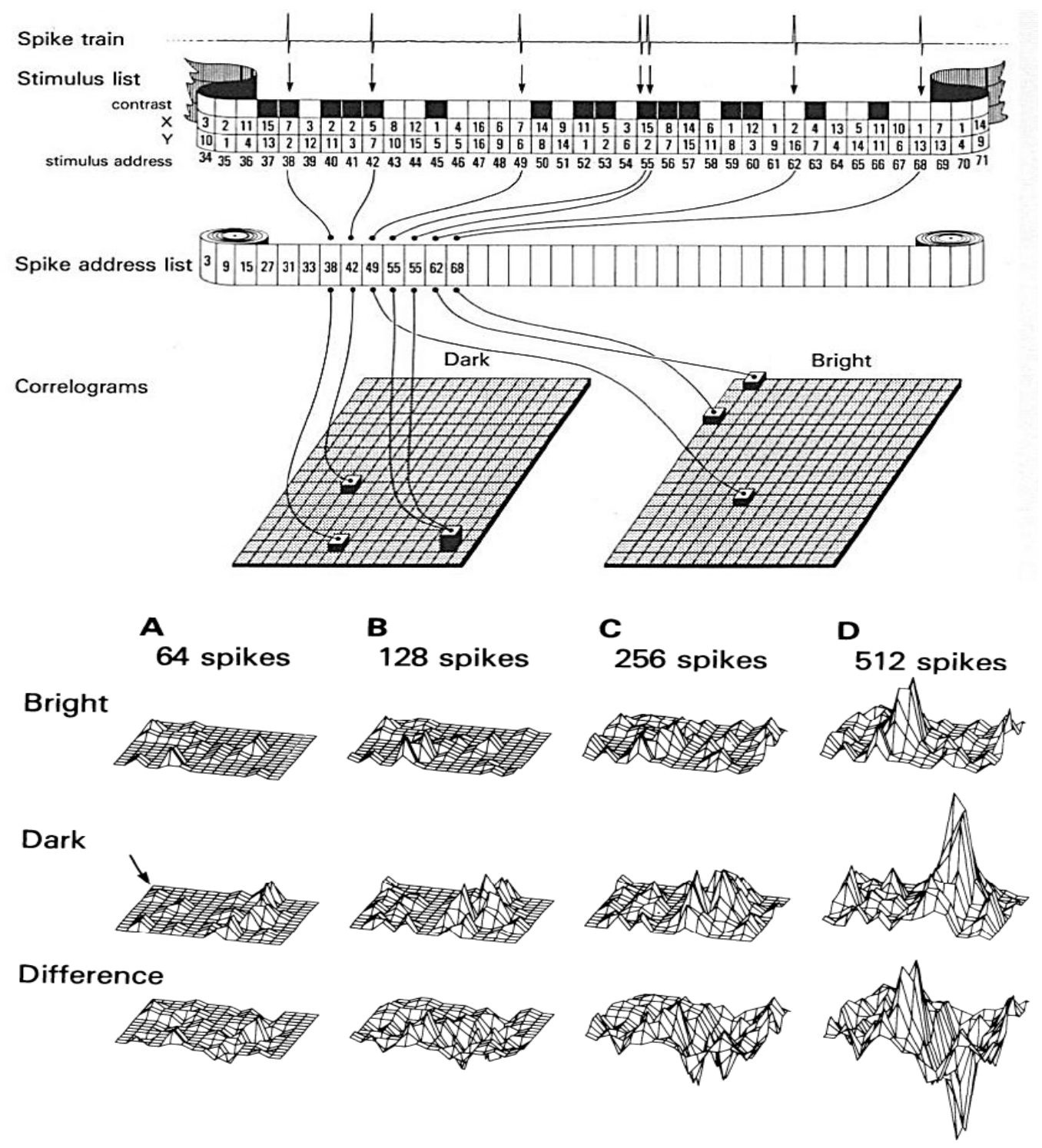

Figure 3.Diagram of the procedure for calculating the spike-triggered average (STA) when using sparse noise stimuli. In the STA every spike was correlated with stimuli at a different time delay. As spike numbers increased, random spontaneous firing averaged out, and structure of the receptive field emerged. From Jones \& Palmer, 1987. 
general temporal frequency preference of the cell. Twelve drifting directions (separated from each other by 30 degrees) were used in the test. Stimuli for each direction were presented for 1-sec five times in random order; each stimulus presentation separated by 1 second of blank screen(on-cells had a dark inter-stimuli blank screen, off-cells had a bright inter-stimuli blank screen, on-off cells had a gray inter stimuli blank screen). In the grating temporal frequency test, spatial frequency and direction of movement were optimized. Testing frequency included $1 \mathrm{~Hz}, 3 \mathrm{~Hz}$, $10 \mathrm{~Hz}, 15 \mathrm{~Hz}, 20 \mathrm{~Hz},-30 \mathrm{~Hz}$, and $60 \mathrm{~Hz}$.For each temporal frequency stimuli were presented for 2-sec five times by random order; each stimulus presentation was separated by 2 seconds of blank screen (on-cells had a dark inter-stimuli blank screen, off-cells had a bright inter-stimuli blank screen, on-off cells had a gray inter stimuli blank screen). Speed tuning for RDKs was also tested. The size, density and direction of dots was optimized for each cell. The speed range was from 5 to 200 degrees/sec, and motion direction coherence was $100 \%$. Stimuli for each RDK speed was presented for 3 seconds three times by random order; each stimulus presentation was separated by 2 seconds of blank screen(on-cells had a dark inter-stimuli blank screen, off-cells had a bright inter-stimuli blank screen, on-off cells had a gray inter stimuli blank screen). Last, first-order STRFs were mapped using sparse noise stimuli (the algorithm is shown in Figure 3, from Jones \& Palmer, 1987), and spike triggered average (STA) methods. For the sparse noise stimuli, small squares (covering 0.3-0.5 degrees of the visual field) were briefly flashed(25 ms)one at a time in rapid succession on a gray background at random locations, with random binary contrast 
polarity on a $16 \times 16$ grid that covered the RF of the cell under testing. For each location in the grid, bright and dark squares were each presented 40 times.

Data analysis

Simple and complex cells are classified by the F1/F0 ratio (Hubel \& Wiesel, 1959, 1962), where F0 is cell's the average firing rate to its preferred grating stimuli and $\mathrm{F} 1$ is the modulation depth of cell's firing rate to its preferred grating. If $\mathrm{F} 1 / \mathrm{F} 0>1$, the cell was classified as simple cell. If $\mathrm{F} 1 / \mathrm{F} 0<1$, the cell was classified as complex cell. To calculate temporal frequency tuning curves for flash and grating stimuli, 2 seconds of average firing rate to each frequency was first Fourier transformed, then the peak amplitudes at each tested frequency in the Fourier spectrum were used to plot the tuning curve. Direction and orientation selectivity were quantified by the following two circular variance indexes, DSI (direction selectivity index $)=\frac{\left|\sum_{\theta} R_{\theta}\left\{\cos \left(\frac{\pi \theta}{180}\right)+i \cos \left(\frac{\pi \theta}{180}\right)\right\}\right|}{\sum_{\theta} R_{\theta}}$, and OSI (orientation selectivity index $)=\frac{\left|\sum_{\theta} \mathrm{R}_{\theta}\left\{\cos \left(\frac{2 \pi \theta}{180}\right)+\mathrm{i} \cos \left(\frac{2 \pi \theta}{180}\right)\right\}\right|}{\sum_{\theta} \mathrm{R}_{\theta}}$, where $\theta$ is grating drifting direction, $\mathrm{R}_{\theta}$ is cell's firing rate to that direction minus spontaneous average firing rate between stimuli presentation and $\mathrm{i}$ is square root of -1 . The direction tuning and temporal frequency tuning curves of simulated cell responses were calculated the same way as measured cell responses. To measure the overlap index of receptive fields sub-regions, "on" and "off" sub-regions were first fitted with 2D Gaussian functions: $f(x, y)=A \exp \left(-\left(a\left(x-x_{0}\right)^{2}+2 b\left(x-x_{0}\right)\left(y-y_{0}\right)+c\left(y-y_{0}\right)^{2}\right)\right)$, where $a=\cos ^{2} \theta / 2 \sigma_{x}{ }^{2}+\sin ^{2} \theta / 2 \sigma_{y}{ }^{2}, b=$ $-\sin 2 \theta / 4 \sigma_{x}{ }^{2}+\sin ^{2 \theta} / 4 \sigma_{y}{ }^{2}, c=\sin ^{2} \theta / 2 \sigma_{x}{ }^{2}+\cos ^{2} \theta / 2 \sigma_{y}{ }^{2}$, then the spatial overlap index were 
defined as: overlap index $=\left(\sigma_{\text {on }}+\sigma_{\text {off }}-\mathrm{d}\right) /\left(\sigma_{\text {on }}+\sigma_{\text {off }}+\mathrm{d}\right)$, where $\sigma_{\text {on }}$ and $\sigma_{\text {off }}$ are averages of $\sigma_{\mathrm{x}}$ and $\sigma_{\mathrm{y}}$ for "on" and "off" sub region respectively, $\mathrm{d}$ is the distance between "on" and "off" center.

To quantify relative preference to different stimuli, cells' highest average response to all temporal frequency/speed tested were calculated for flash $\left(\mathrm{A}_{\text {flash }}\right)$, grating ( $\left.\mathrm{A}_{\text {grating }}\right)$ and RDKs $\left(\mathrm{A}_{\mathrm{RDKs}}\right)$ stimuli, and then two index were calculated, grating/flash index $=\mathrm{A}_{\text {grating }} / \mathrm{A}_{\text {flash}} ;$ dots/flash index $=\mathrm{A}_{\mathrm{RDKs}} / \mathrm{A}_{\text {flash }}$.

For analysis of sparse noise data, each spike was assigned to the stimulus that preceded it by a delay period. Specifically, to calculate the spike triggered average at a certain time difference $t$, the following formula was used: $\mathrm{A}\left(\mathrm{x}, \mathrm{y}, \mathrm{t}^{\prime}\right)=\sum_{\mathrm{n}} \mathrm{Sn}\left(\mathrm{x}, \mathrm{y}, \mathrm{t}-\mathrm{t}^{\prime}\right)$, where $\mathrm{A}$ is the spike triggered average, $\mathrm{n}$ is number of spikes in the whole test, $\mathrm{x}$ and $\mathrm{y}$ are the locations of bright and dark squares in the stimuli grid, $\mathrm{t}$ are times of spikes and $\mathrm{S}_{n}$ represents the luminance polarities at specified location and time in the stimuli ensemble. To get the linear predictions of cells' response to sine-wave gratings, 1 second of sine-wave grating were convolved with250ms of STRFs of the cells in the MATLAB, and then the results were rectified to turn any negative parts into 0 . To compare physiological measured data with model prediction, parameters (etc. temporal frequency, spatial frequency, orientation) of the sinewave grating used in modeling phase were kept same as in physiological recording phase. Noise defined as below $10 \%$ of peak amplitude in STRFs were 
removed prior convolution. 


\section{RESULTS}

Data is presented from a total of 246 cells, as described in Table1, from 17 normally reared and 19 RLR tree shrews. Of the 112 cells recorded from normally reared animals $30 \%$ were complex cells and $70 \%$ were simple cells. The spatial temporal receptive fields (STRFs) of 70 cells were measured in normally-reared animals. In RLR animals, 134 cells were recorded, with $25.3 \%$ being classified as complex cells and $74.7 \%$ as simple cells. The STRFs of 85 cells were measured in RLR animals. In each case, the cells' response selectivity (i.e., orientation tuning, temporal frequency tuning, and stimuli preference) was first measured, then the receptive field structure were estimated using sparse noise stimuli. The response of a representative cell to different stimuli used is shown in Figure4.

Table 1

\begin{tabular}{llllllll}
\hline & $\begin{array}{l}\text { Total } \\
\text { number of } \\
\text { cells } \\
\text { recorded }\end{array}$ & $\begin{array}{l}\text { Layer } \\
\text { II/III }\end{array}$ & $\begin{array}{l}\text { Layer } \\
\text { IV }\end{array}$ & $\begin{array}{l}\text { Layer } \\
\text { V/VI }\end{array}$ & $\begin{array}{l}\text { Simple } \\
\text { cells }\end{array}$ & $\begin{array}{l}\text { Complex } \\
\text { cells }\end{array}$ & $\begin{array}{l}\text { STRF } \\
\text { measured }\end{array}$ \\
& 112 & 19 & 66 & 23 & 77 & 33 & 70 \\
\hline $\begin{array}{l}\text { Normally } \\
\text { rearing }\end{array}$ & & 30 & 78 & 25 & 100 & 34 & 86 \\
$\begin{array}{l}\text { Red } \\
\text { reared } \\
(\text { RLR })\end{array}$ & 134 & & & & & & \\
\hline
\end{tabular}

note: In normally reared group, 2 cells were not classified as simple/complex, since the response to grating were too low. 
A)

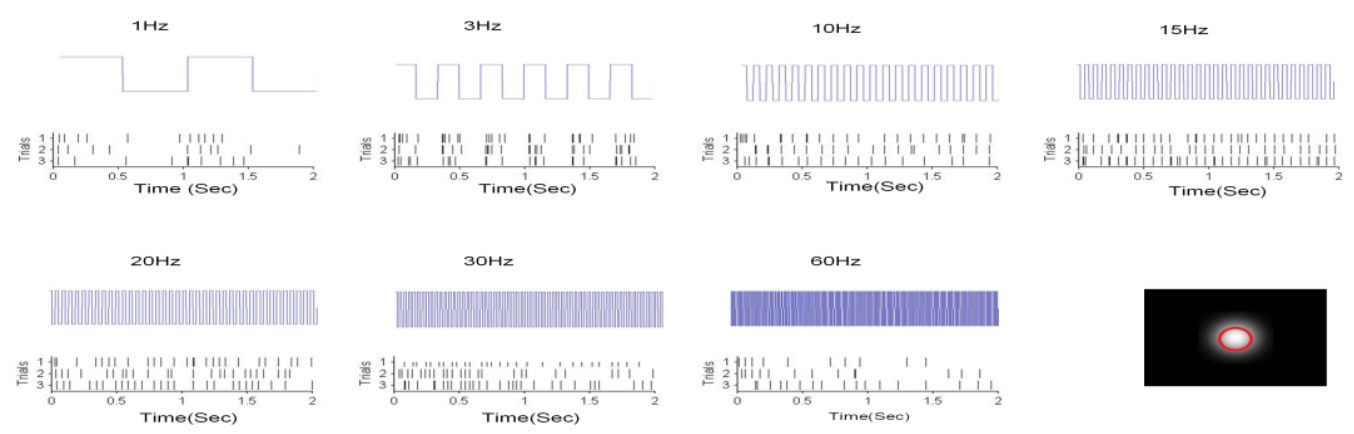

B)

Drifting sinewave grating
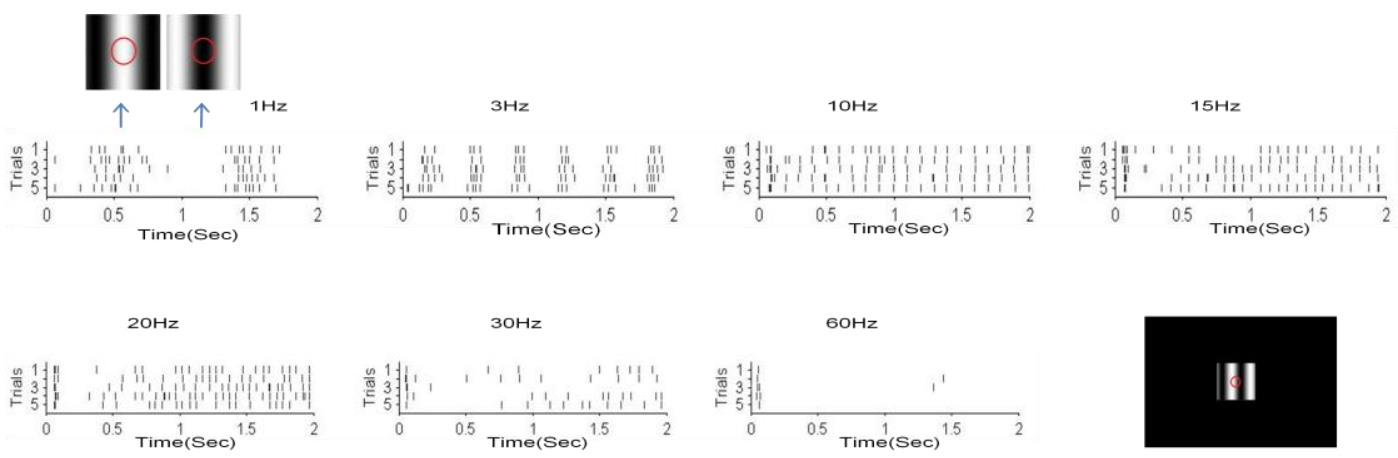

III

C)

Random Dot Kinematogram
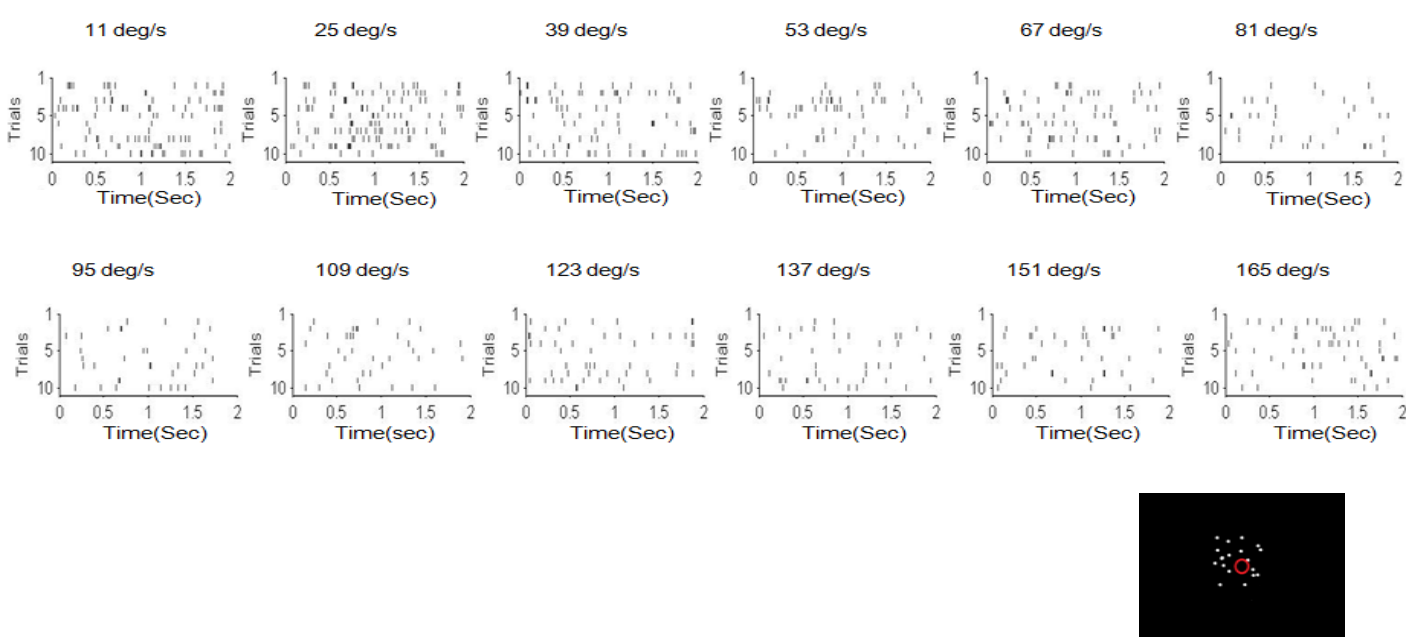

Figure 4.Representative neuron responses to different motion stimuli. Red circles in the stimuli snapshots represent the receptive field of the cells. A)-C) came from different neurons. A) Representative response to flash stimuli B)Representative response to drifting grating stimuli C) Representative response to RDK stimuli 


\section{Diverse STRF features in both space and time was found in tree shrew}

\section{V1, but the proportion of different RF types did not differ across cortical layers.}

A diversity of spatial-temporal RF structure was found in the data, and classified into two types as shown in Figure 5. Type I cells had spatially continuous "on" or "off" regions in their X-Y map(Figure5A), or had their "on" or "off" region peak shifted in location over time. Type II RFs have spatially continuous "on" and "off" regions in the $\mathrm{X}-\mathrm{Y}$ map, and both regions could be fitted by a 2D Gaussian function. The number of these two types of RFs in different layers are shown in Table 2. In all cortical layers of normally reared animals, Type II RFs were more common than Type I RFs (Layer IV: Type I 28.6\%, Type II 71.4\%; Layer II/III: Type I 27.4\%, Type II 72.6\%; Layer V/VI: Type I 25\%, Type II 75\%). Red light rearing appeared to increase the proportion of Type I cells in all layers, but this change was not statistical significant in our sample. (chi-square tests, Layer IV: $\chi^{2}=1.2494, \mathrm{P}=0.2637$,Layer II/III: $\chi^{2}=0.9392, \mathrm{P}=0.3325$, Layer V/VI: $\chi^{2}=1.3421, \mathrm{P}=0.2467$, summed across layers: $\chi^{2}=3.6619, \mathrm{P}=0.057$ ).

\section{Table 2}

\begin{tabular}{lllll}
\hline & & $\begin{array}{l}\text { Layer } \\
\text { II/III }\end{array}$ & Layer IV & $\begin{array}{l}\text { Layer } \\
\text { V/VI }\end{array}$ \\
\hline Normally & Number of Type I RF measured & 2 & 14 & 3 \\
reared & Number of Type II RF measured & 5 & 37 & 9 \\
Red light & Number of Type I RF measured & 9 & 20 & 7 \\
rearing & Number of Type II RF measured & 9 & 33 & 8 \\
(RLR) & & & & \\
\hline
\end{tabular}

The temporal aspect of each RF was measured by calculating the difference between "on" and "off" regions in X-T time as displayed in Figures 6 and 7. For both types of RFs and both groups of animals, the majority of cells had both an "on" and 
A. Spatial RF profile (X-Y map)

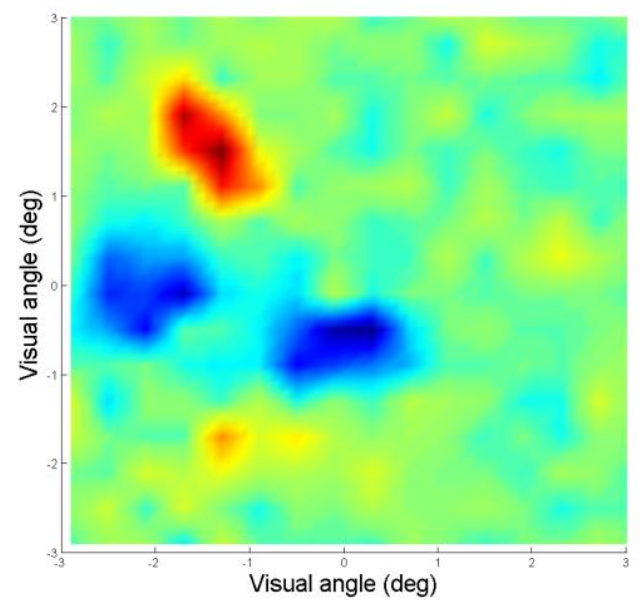

B. Spatial RF profile (X-Y map)
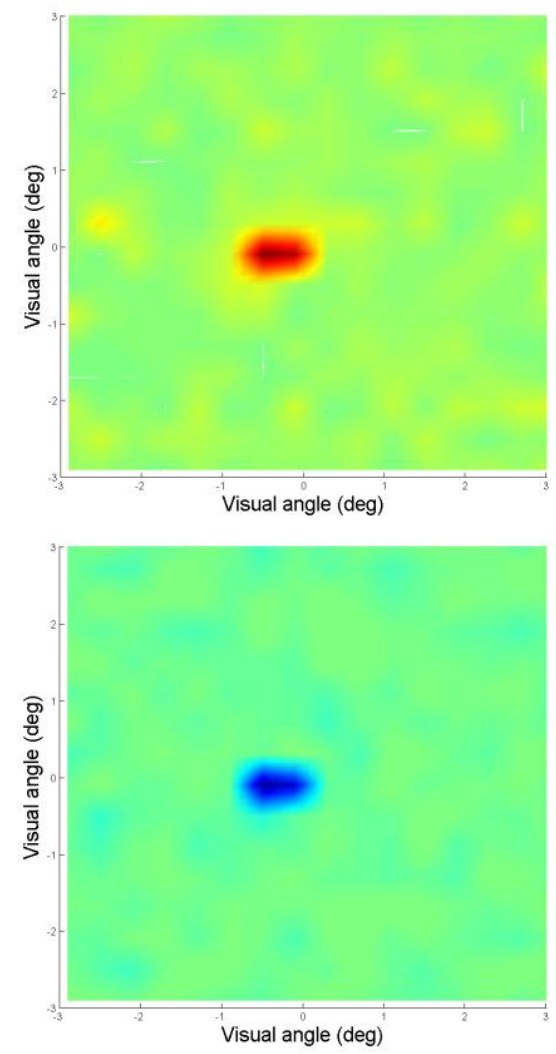

Spatiotemporal RF profile (X-T map)

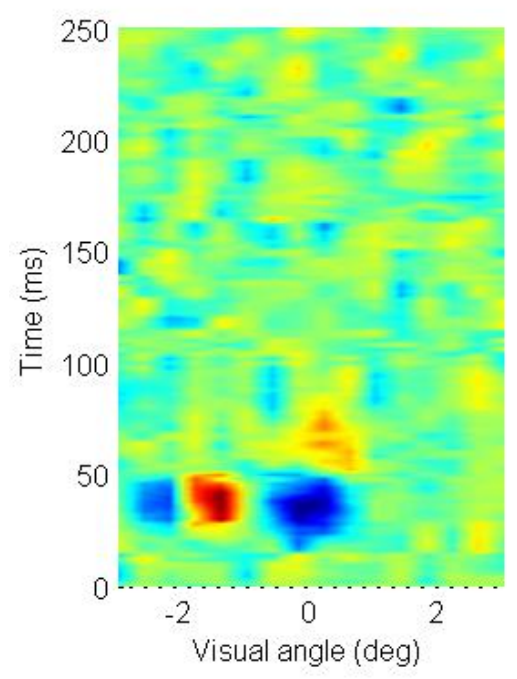

Spatiotemporal RF profile (X-T map)

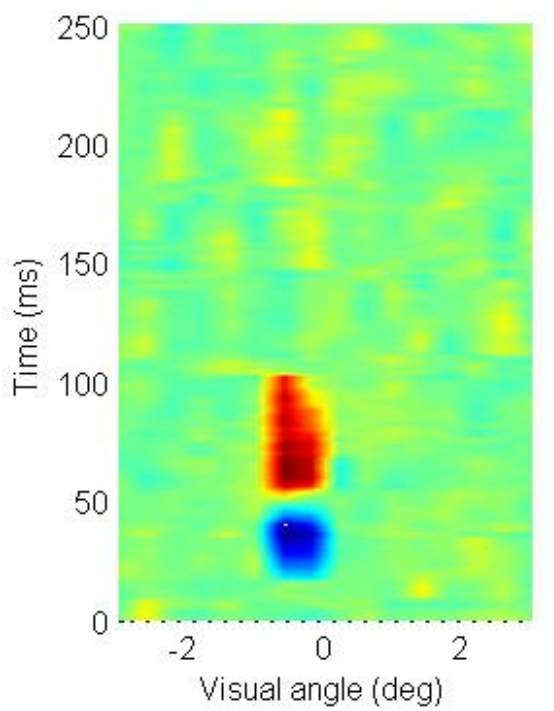

Figure 5. Representative spatial and temporal structures of Type I and Type II Receptive fields.The complete spatial temporal receptive profile is a function of three independent variables: $X, Y$, and $T$. $X$ and $Y$ are the two spatial dimensions of the receptive field, and $T$ is time. Left: Spatial RF profiles (X-Y map). Right: Spatiotemporal RF profiles (X-T). A) A representative Type I cell where "on" or "off" regions are spatially discontinuous. B) A representative Type II cell where "on" or "off" regions are spatially continuous and both can be fitted with a 2D Gaussian function. 
A.

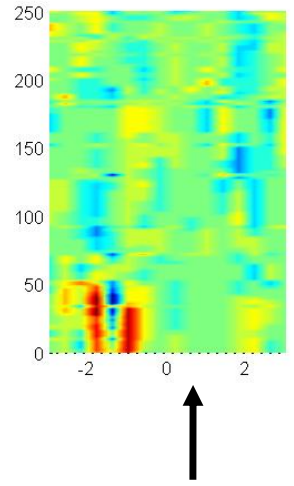

B.

Peak time difference (ms)

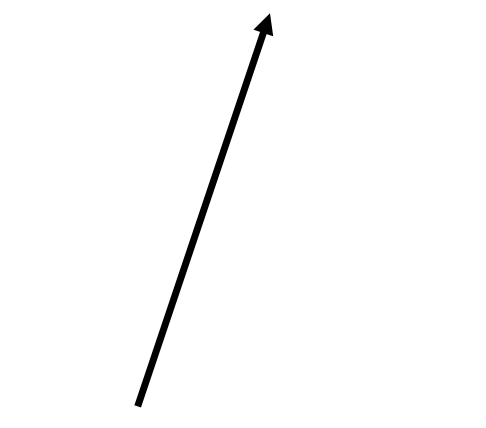

Peak time difference (ms)

\section{Peak time difference (ms)}
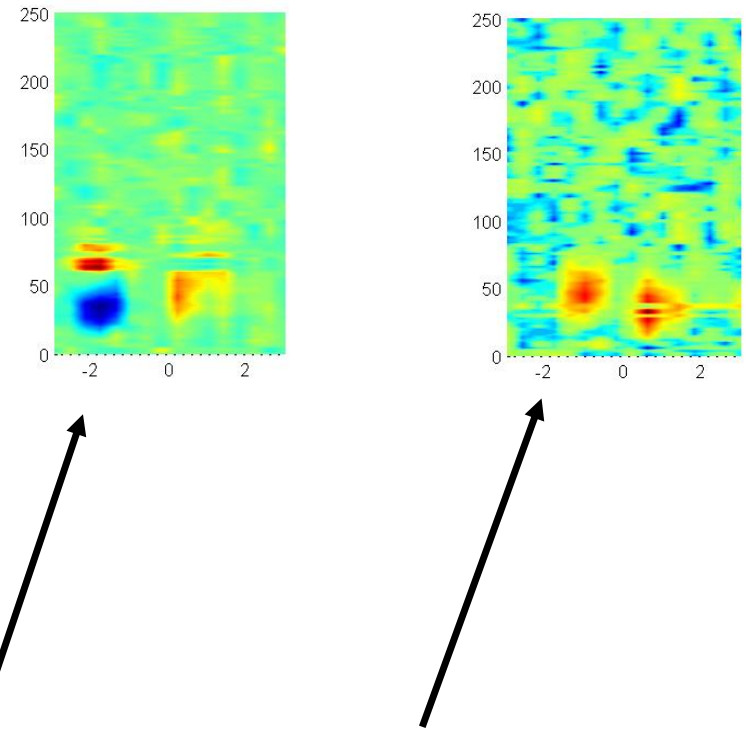

Figure 6.Distribution of temporal difference between "on" and "off" peaks for Type I RFs. A) Data for normally reared animals. Three representative RF X-T maps with different peak time difference are displayed, with a corresponding histogram show that most peak-to-peak time difference is shorter than $20 \mathrm{~ms}$. B) Data for RLR animals. In both normally reared and RLR groups the relatively short interval ( $<20 \mathrm{~ms}$ ) between "on" and "off" are more common. No significant difference was found between the two groups (Mann-Whitney test, $\mathrm{P}=0.2041$ ). 
A
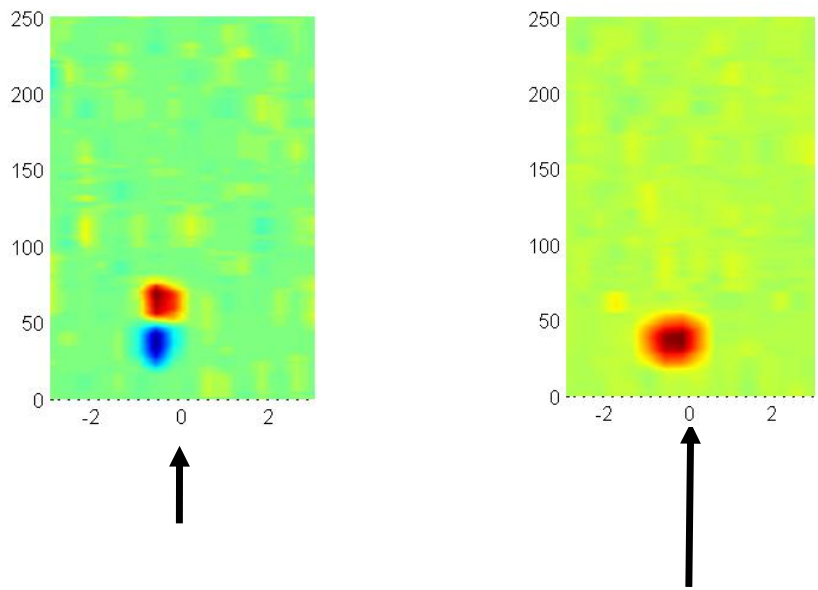

Peak time difference (ms)

B

Peak time difference (ms)

Figure 7. Distribution of the temporal difference between "on" and "off" peaks for Type II RFs. A) Data for normally reared animals. Two representative RF X-T maps with different peak time difference are displayed, with the corresponding histogram that shows that most peak-to-peak time different is shorter than $20 \mathrm{~ms}$. B) Data for RLR animals. In both normally reared and RLR groups the relatively longer interval (>20 ms) between "on" and "off" are more common. No significant difference was found between two groups (Mann-Whitney test, $\mathrm{P}=0.1362$ ). 
"off" "blob" in the X-T map, but the distribution of "on-off interval" is different for Type I and Type II RFs. In normally-reared group, for Type I cells have both "on" and "off" regions in X-T maps, relatively short intervals ( $<20 \mathrm{~ms})$ between "on" and "off" were more common, while these intervals are relatively longer $(>20 \mathrm{~ms})$ in Type II cells, though this is not the case in RLR group (Normally reared group: Kolmogorov-Smirnov test, $\mathrm{p}=0.029$; RLR group: Kolmogorov-Smirnov test, $\mathrm{p}=0.5202$; median for normal Type I group, $15.5 \mathrm{~ms}$; median for RLR Type I group, 23ms;median for normal Type II group, 28ms; median for RLR Type II group, 32.5 ms). No significant difference was found between normally reared and RLR groups (Type1, Kolmogorov-Smirnov test, $\mathrm{p}=0.4688$; Type2, Kolmogorov-Smirnov test, $\mathrm{p}=0.0731)$.

The degree of spatial overlapping of Type II cells with both "on" and "off" blobs were measured with an "Overlap Index" (See Methods).An Overlap Index equal to 1 means perfectly overlapped "on" and "off” regions. An Overlap Index equal to 0 means tangent "on" and "off" regions, and an overlap index smaller than 0 means "on" and "off" sub-regions are further apart and no overlap. In both normally reared and RLR groups, "on" and "off” regions are highly overlapped as shown in Figure 8. (Median for normal group $=0.6691$; Median for normal group $=0.6831$ ). The aspect ratio of RF Type II RFs were also measured in our sample in normally and red light reared group, both showing peaks at around 1.5. 
Figure 8. Distribution of spatial Overlap Index and aspect ratio for type II RFs in normally reared (A) and RLR animals (B). An Overlap Index equal to 1 means perfectly overlapped "on" and "off" regions. An Overlap Index equal to 0 means tangent "on" and "off" regions. In both normally reared and RLR groups, "on" and "off" regions are highly overlapped. Aspect ratios were calculated by dividing the RF lengths by RF widths. In both Normally reared and RLR group, aspect ratio peaked at around 1.5, which is much smaller than that of simple cells in cats and macaque monkey (DeAngelis, Ohzawa \& Freeman ,1993; Ringach ,2002). 
Lamina analysis showed that grating preferring cells were found in layer IV and V/VI, but not in layer II/III, while red light rearing decreased this heterogeneity. No RDKs preferring population was found. Stimuli preference was quantified by comparing each cell's average firing rate to different stimuli as shown in Figure 9 and 10. In layer IV and layer V/VI of the normally reared group, cells were clustered based on their preference for grating stimuli over flash stimuli. This is indicated by multiple peaks in the grating/flash histogram shown in Figure 9B). In contrast, there is only one peak in the dots/flash histogram across all layers (see Figure 9C). Red-light rearing seems to flatten the multiple peak distribution of the grating/ flash stimulus responses in layer IV though VI into a single peak distribution (Kolmogorov-Smirnov test, $\mathrm{p}=0.0107$; see Figure $10 \mathrm{~B}$ ). To test if the multiple peaks in grating/flash histogram correlates with any known cell type categorizations, stimulus preference data were further analyzed in simple cell population alone(Figure 11.A), by orientation selectivity (Figure 11. B), and by RF types (Figures 12.and 13.), but no evidence was found that different peaks in grating/flash histogram can be attributed to any of these properties.

Layer IV cells display highest modulation depth to grating stimuli, while in layer II/III red-light-rearing decreases cells' modulation depth to grating stimuli. Overall, in normally reared animals, the median of F1/F0 ratio in layer IV is slightly higher than that of other layers, though the population distributions was not significantly different in our sample ( layer II/III and layer IV: Kolmogorov-Smirnov 
A.

B.

Layer IV

Layer II/III

Layer V/VI

Figure 9. Stimulus preference of cells in normally reared animals across cortical layers. A)Scatter plot of stimulus preference. The X-axis is the cell's average response firing rate to the grating stimulus divided by that in response to the flash stimulus. The $Y$-axis is the cell's average response firing rate to RDKs(dots) divided by that to the flash. Blue dots represent layer IV cells, red dots represent layer II/II cells, green dots represent layer V/VI cells. B) Histogram of grating/flash across layers. C)Histogram of dots/flash across layers. Note in layer IV and V/VI there are clearly multiple peaks in grating/flash histogram but not in the dots/flash histogram. 
A.

B.

Layer IV

Layer II/III

Layer V/VI

Figure 10. Stimulus preference of cells in RLR animals across cortical layers. A) Scatter plot of stimuli preference. The $X$-axis is cell's average response firing rate to the grating stimulus divided by that in response to the flash stimulus. The $Y$-axis is cell's average response firing rate to RDKs (dots) divided by that to the flash. Blue dots represent layer IV cells, red dots represent layer II/II cells, green dots represent layer V/VI cells. B) Histogram of grating/flash across layers. C)Histogram of dots/flash across layers. 
A.

Normally reared

RLR

Layer IV

Layer II/III

Layer V/VI

B.

Figure 11. A) Stimuli preference in different cortical layers for simple cells. Note there is still obvious bimodal distribution in layer IV. B) Lower panel: Histogram of orientation tuning circular variance; Higher panel: scatter plot of circular variance and grating/flash response ratio. 
A.

B.

Figure 12. Stimuli preference of cells with different RF structures in normally reared animals. A) Scatter plot of stimuli preference. The X-axis is cell's average response firing rate to the grating stimulus divided by that in response to the flash stimulus. The $\mathrm{Y}$-axis is cell's average response firing rate to dots divided by that to flash. B) Histogram of grating/flash for cells with Type I (upper panel) and Type II (lower panel) RFs. C) Histogram of dots/flash for cells with Type I (upper panel) and Type II (lower panel) RFs. 
A.

B.

Figure 13. Stimuli preference of cells with different RF structures in RLR animals. A) Scatter plot of stimuli preference. The $\mathrm{X}$-axis is cell's average response firing rate to the grating stimulus divided by that in response to the flash stimulus. The $\mathrm{Y}$-axis is cell's average response firing rate to RDKs (dots) divided by that to the flash. B) Histogram of grating/flash for cells with Type I (upper panel) and Type II (lower panel) RFs. C) Histogram of dots/flash for cells with Type I (upper panel) and Type II (lower panel) RFs. 
test, $\mathrm{p}=0.4868$; layer V/VI and layer IV: Kolmogorov-Smirnov test, $\mathrm{p}=0.1323$; Figure 14A). Interestingly, red light rearing seemed to caused an increase in the proportion of complex cells in layer II/III as shown in Figure 14B and 14D(Normal layer II/III median=1.2616; RLR layer II/III median=0.9043, Kolmogorov-Smirnov test, $\mathrm{p}=0.0633$ ), and as a result making an significant difference between layer II/III and layer IV in F1/F0 distribution (Mann-Whitney test, $\mathrm{p}=0.0113$ ).In cat and primates, the RF spatial separation co-varies with F1/F0 ratio, simple cells have both high F1/F0 ratio and well separated RFs. However this is not the case in tree shrew. First, in our sample Type I RFs have higher proportion of complex cells (Table 3.), second, there is not negative relationship between RF separation and F1/F0 (Normally reared group, Pearson's r=0.011, Adj. $\mathrm{R}^{2}=-0.0311$. RLR group, Pearson's r=0.2269, Adj. $\mathrm{R}^{2}=-0.0188$.). The relationship between F1/F0 ratio and the "On" and "Off" balance was also investigated. In both normally reared and RLR groups, "On" and "Off" strength ratiowere relatively widely distributed between 0 and 1 , and no obvious peaks were found. No linear relationship was found between F1/F0 and "on" and "off" balance as shown in Figure 15 (Normally reared group: Pearson's r=0.1128, Adj. $\mathrm{R}^{2}=-0.0022$; RLR group: Pearson's r=-0.0284, Adj. $\left.\mathrm{R}^{2}=-0.0111\right)$.

Table 3.

\begin{tabular}{llllll}
\hline & & $\begin{array}{l}\text { Total cells } \\
\text { recorded }\end{array}$ & $\begin{array}{c}\text { STRFs } \\
\text { recorded }\end{array}$ & Type I & $\begin{array}{l}\text { Type } \\
\text { II }\end{array}$ \\
\hline Normally reared & Simple Cell & 77 & 53 & 11 & 42 \\
& Complex Cell & 33 & 17 & 8 & 9 \\
\multirow{2}{*}{ RLR } & Simple Cell & 100 & 57 & 23 & 34 \\
& Complex Cell & 34 & 29 & 16 & 13 \\
\hline
\end{tabular}


A.

B.

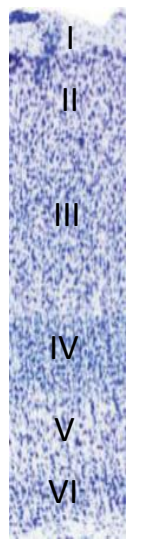

C.

D.

Figure 14. Laminar organization of F1/F0 ratio for normally reared and RLR animals. A, B) Scatter plot of F1/F0 at different normalized depth in normally reared and RLR animals. Plot adjacent to a scaled photomicrograph of a Nissl-stained section of tree shrew V1 cortex. The color-coded line is the median at different depth calculated using a sliding 0.1 wide window with 0.01 steps. C, D)Distribution of F1/FO ratio in different layers of normally reared and RLR animals. 
A.

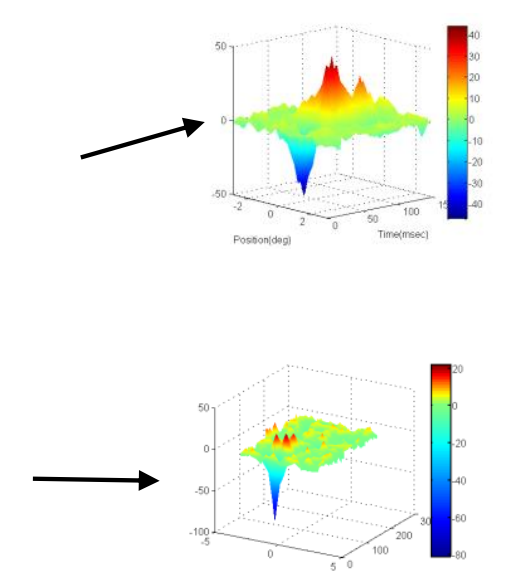

Percentage (\%)

Percentage (\%)

B.

Figure 15. A) Scatter plot of "On-Off balance index" and F1/F0 in normally reared and RLR animals. The relative strength of "on" and "off" response were quantified by an "on-off" balance index, which equals to the smaller of "on" or "off" response measured in reverse correlation test divide by the larger of "on" or "off" response. The index ranges from 0 to 1. A value of zero indicates a response to only one contrast polarity, A value of 1 indicates that the cell's response strength to "on" and "off" are about same. Two representative cells with high and low "On-Off" balance index are shown on the right. B) Scatter plot of F1/F0 and spatial overlap index of Type II RFs. Normally reared group, Pearson's $r=0.011$, Adj. $R^{2}=-0.0311$. RLR group, Pearson's $r=0.2269$, Adj. $R^{2}=-0.0188$. 
Although both temporal frequency band-pass and low-pass cells can be identified in tree shrew V1, the proportions of each tuning curve types are different across cortical layers. No significant effects were found in neurons from the RLR group in terms of averaged tuning curves to different frequencies. The temporal frequency tuning curves were measured with sine-wave gratings and then normalized. Figure 16A shows the distribution of normalized response at different temporal frequencies for cells in normally reared animals. Each dot represents one cell's normalized response to a specific frequency. It is clear that at 1 $\mathrm{Hz}, 10 \mathrm{~Hz}, 15 \mathrm{~Hz}$ and $20 \mathrm{~Hz}$ there are multiple peaks, suggesting potential multiple mechanisms in temporal processing. Thus cells are classified into three categories based on their turning curve shapes. If the normalized response to $1 \mathrm{~Hz}$ is below 0.65 , the cell was classified as band-pass, otherwise it was classified as low-pass. Low-pass cells were further classified as high-cutoff and low-cutoff based on their average response to $10 \mathrm{~Hz}, 15 \mathrm{~Hz}$ and $20 \mathrm{Hzas}$ shown in Figure 16B. The proportion of cells with different tuning curves in each layer are shown in Figures 17A-17C. In general, low-pass high cutoff cells are less commonin layer II/III than in layer IV (Chi-square test: $\chi^{2}=7.553, \mathrm{P}=0.023$ ) and V/VI (Chi-square test: $\left.\chi^{2}=5.834, \mathrm{P}=0.055\right)$. Red light rearing also seemed to modify the proportion of different tuning curves in layer IV (Chi-square test: $\chi^{2}=5.894, \mathrm{P}=0.052$ ), but did not have a significant effect on summed tuning curve in each layer (biggest median difference in layer II/III at $1 \mathrm{~Hz}$, Kolmogorov-Smirnov Test, $\mathrm{p}=0.2839$ ). It was also found that layer II/III cells had 
A.

B.

Figure 16. A) Distribution of normalized responses at different temporal frequencies for cells in normally reared animals. Each dot represent one cell's normalized response to a specific frequency, bin $=0.05$. Note that at $1 \mathrm{~Hz}$ and from $10-20 \mathrm{~Hz}$, there are multiple peaks, indicating potentially different mechanisms in temporal processing. B) Normalized tuning curve for low-pass and band-pass cells. Cells were classified into three categories based on the shape of their temporal tuning curve. If the normalized response to $1 \mathrm{~Hz}$ is below 0.65 , the cell will be classified as band-pass, otherwise it is a low-pass. Low-pass cells were further classified as high-cutoff and low-cutoff based on their average response to $10 \mathrm{~Hz}, 15 \mathrm{~Hz}$ and $20 \mathrm{~Hz}$. The length of the error bar in the graph represent standard error. 
Layer IV

B.

C.

Layer II/III

\section{Layer V/VI}

Figure 17. A-C)Left: Proportion of cells with different tuning curves across layers. Right: Median for normalized response at different temporal frequencies for normally reared and RLR animals. Length of error bar represents standard error. The histogram shows that in general, low-pass high-cutoff cells are more common in layer IV $\left(X^{2}=7.553, P=0.023\right)$ and $\mathrm{V} / \mathrm{VI}\left(\chi^{2}=5.834, P=0.055\right)$ than in layer II/III. Red light rearing also seems to change the proportion of different tuning curves in layer IV $\left(\chi^{2}=5.894, P=0.052\right)$, but did not have significant effect on summed turning curve in each layer. 
lower responses to $15 \mathrm{~Hz}$ (Kolmogorov-Smirnov test, $\mathrm{p}=0.01039$ ) and $20 \mathrm{~Hz}$ (Kolmogorov-Smirnov test, $\mathrm{p}=0.01121$ ) compared to layer IV.

\section{The linear model does not provide a good prediction for temporal}

frequency tuning. A linear model was used to predict temporal tuning properties based on the STRF of cells. As shown in Figure 18, overall, the model predicted more sharply tuned cells than were measured. For cells with single polar RFs, the linear model predicted a sharper tuned low-pass tuning curve, which overestimates the low frequency end and underestimates the response for higher frequency. For cells with both "on" and "off" region in STRFs, the result of the linear model predicted a sharper band-pass curve compared to measured data. A representative cell is shown in Figure 18C. As evident, this cell with "on" and "off" blobs separated by 40ms was predicted to peak at $12.5 \mathrm{~Hz}$ by the linear model, but the measured data revealed a peaked at $3 \mathrm{~Hz}$.

Finally, measurement of the laminar organization of orientation tuning revealed that in both groups, cells in layer II/III tended to have a higher median orientation tuning index than layer IV (Normally reared group: layer IV median=0.1356, layer II/III median=0.2203, layer V/VI median=0.1809, Mann-Whitney test between layer IV and layer II/III, p=0.0379; RLR group: layer IV median $=0.1559, \quad$ layer $\quad$ II/III median $=0.3089$, layer $\quad \mathrm{V} / \mathrm{VI}$ median=0.1968,Mann-Whitney test between layer IV and layer II/III, $\mathrm{p}=0.0505$ ), as 
Normally

B.

RLR

C.

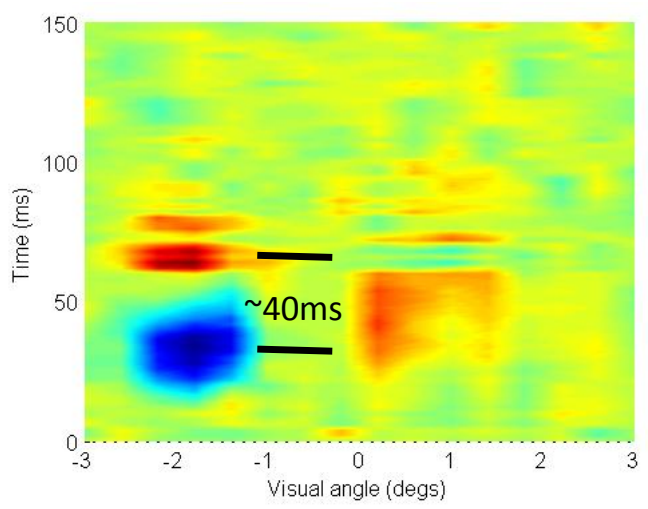

Figure 18. Discrepancy between measured temporal frequency tuning curves and predicted tuning curves. A, B) Normalized measured and predicted tuning curve for Type I and Type II RFs. In both normally reared and RLR animals, a linear model predicted sharper tuned low-pass and band-pass groups, while the measured tuning curves were more flattened. C) Left: X-T map of a representative cell with 40ms interval between "on" and "off" peaks. Right: Normalized measured and predicted tuning curve for the cell shown on the left. A linear model predict a band-pass tuning curve peaks at $\sim 12.5 \mathrm{~Hz}$, while the measured tuning curve peaks at $3 \mathrm{~Hz}$ with a low-pass shape. 
shown in Figure 19A.The linear model failed to predict either the degree or the direction of orientation tuning (see Figure 19B and19C), but the difference between predicted and measured preferred orientation was not randomly distributed. 
A.

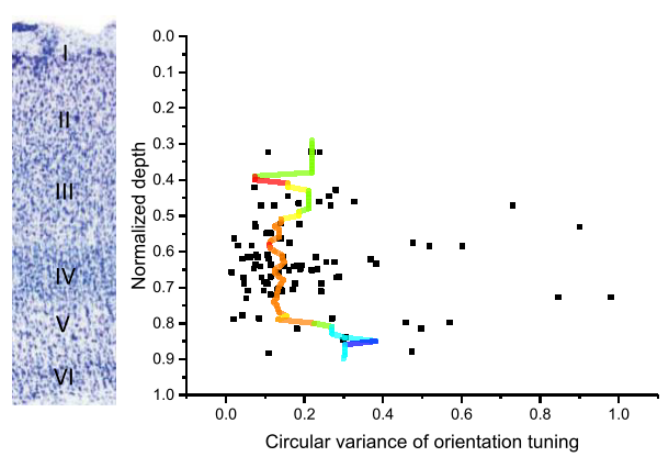

B.

Adj. $\mathrm{R}$ square $=0.00913$
RLR

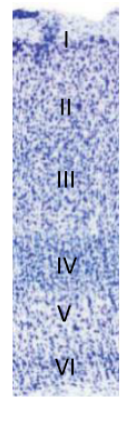

Adj. $R$ square $=-0.00935$

C.

Figure 19. A) Laminar profile of orientation tuning. A) Scatter plots of circular variance of orientation tuning at different normalized cortical depth. Plots are adjacent to a scaled photomicrograph of a Nissl-stained section of tree shrew V1 cortex. The color-coded line is the median at different depths calculated using a sliding 0.1 wide window with 0.01 steps. In both normally reared (left) and RLR (right) groups, layers II/III tend to have a higher median for orientation selectivity than layer IV. B) Scatter plot of measured and predicted orientation tuning index. A Linear model does not capture the degree of tuning in measured data in both normally reared and RLR groups. C) Histogram of the difference between measured and predicted preferred orientation in degrees. The histogram shows that a linear model does not predict the preferred orientation, however the difference between predicted and measured preferring orientation is not randomly distributed. 


\section{DISCUSSION}

Receptive field structure and linear model

The current study is the first comprehensive report on both the spatial and temporal aspects of $\mathrm{V} 1$ receptive field structure in the tree shrew. In this study two types of STRFs were revealed: Type I included cells with spatially discontinuous "on" or "off" regions, or cells with RF centers that shifted in space over time; Type II STRFs were characterized by largely overlapped circular or elliptical "on" and "off" sub-regions. This characterization differs from previous descriptions of the spatial aspect of RF structure of tree shrew V1 neurons. Using similar methodology, Veit and colleagues (2014) only revealed RF types with highly overlapped elliptical "on" and "off" regions, similar to the Type II RFs described in the current study. Possible explanations for this discrepancy may be: 1) due to the smaller size of the sparse noise stimuli used in current study which was only about $1 / 3$ of what was used in Veit et al. (2014),thus permitting our characterization of finer RF structural components; and 2) that the Type II RF neurons we sampled are a minority in V1 cell population. Considering that we also included the "shifting center" RFs into the Type I classification, the spatially discontinuous RF Type II neurons would constitute an even smaller proportion.

The low proportion of complex cells (based on the criteria of F1/F0 ratio)and 
spatially overleaped RF sub-regions we found is in accordance with previous research on tree shrew V1 (Kaufmann \& Somjen, 1979; Veit et al. 2014). In both cats and primates, the separate subfields are thought to be the main contributor to high F1/F0 ratio (Hubel \& Wiesel, 1962, 1968), however, this does not seem to be the case in tree shrews. Despite having high proportion of simple cells, most cells in tree shrew V1 have highly overlapped "on "and "off" sub-regions in spatial domain (see Figure 8.). However, in the current study, the "inflated" F1/F0 ratio does not seems to be caused by "unbalanced on-off" as suggested by Veit et al. (2014). In Veit et al. (2014), "on-off balance" was quantified use an index based on log ratio log, and because the off dominance in their data sample, this log index may make the linear regression analysis more sensitive and less powerful. In our data sample, many cells only respond to one polarity of stimuli, thus log ratio cannot be used. More following studies should be made to solve this discrepancy.

The temporal aspect our data also revealed a difference between species. In cat visual cortex, the distribution peak of the "on-off" interval is around 60ms (DeAngelis et al., 1993), while in tree shrew it is much shorter (20ms was most common for Type II). Of interest is that whereas the peak of the temporal frequency tuning curve is the same in the two species (both at around $3 \mathrm{~Hz}$, DeAngelis et al., 1993), tree shrew cells have a much higher cutoff than cat cells. It is also worth pointing out that the Type I and Type II classification of neurons in our study does not directly correspond to simple and complex types in cat and primates. In primates, 
most simple type RFs have separated "on" and "off" subfields both in space and time, and complex type RFs have overlapped subfields both in space and time (Rust, Schwartz, Movshon \& Simoncelli, 2005; Liu, Liu\& Li, 2007), while in tree shrew it is more intermixed. For example, for Type II RFs, though in the space domain the "on" and "off" are largely overlapped, in temporal domain the peak interval is widely distributed. A linear model was employed in the current study to predict orientation and temporal frequency tuning. It was found that the prediction for orientation is poor. In cat and primates, the linear prediction for orientation tuning only works for simple cell, which mostly have separate "on" and "off" sub-regions (Martinez et al., 2005; Ferster et al., 1996). So this observation agrees with the fact that in tree shrew V1, separate sub-regions are infrequent. It is also in accordance with the idea that the orientation tuning in tree shrew V1 neurons is largely contributed by nonlinear intra-cortical mechanisms (Fitzpatrick, 1997; Chisum et al., 2003; Mooser et al., 2004). The linear prediction of temporal frequency tuning is also not very accurate, especially for the cells with a bipolar structure of their X-T map, raising the possibility that nonlinearity also plays an important role in temporal information processing.

Lamina transformation of RF properties

In cat visual cortex, layer IV cells display dramatically different properties from LGN cells. Most layer IV cells exhibit orientation tuning to grating stimuli, and a high percentage exhibit direction tuning for motion (Reid \& Alonso, 1995; Ferster et 
al., 1996).However, our results in tree shrew confirmed previous findings that, orientation tuning emerges in layer II/III (not in layer IV) in this species. We also found that similar to cat and primates (Gilbert, 1977), tree shrew layer IV cells have the highest F1/F0 ratio across cortical layers, but in contrast to cats and primates, the F1/F0 ratio in the tree shrew is not strongly correlated with first order RF structures measured with sparse noise stimuli. This suggests the presence of a different mechanism in tree shrews. In the current study, we identified both a band-pass and a low-pass mechanism to be present, and the proportions of band-pass cells and low-pass cells across cortical layers were also measured. Different types of temporal tuning shapes were found in Layer IV neurons compared to Layer II/III neurons. In general, Layer IV cells respond more vigorously to higher frequency stimuli than did cells in the superficial layers. This suggests that, similar to primates ( Hawken, Shapley \& Grosof, 1996), a second order low-pass filter exists between the granular layer (layer IV) and the supra-granular layers (layers II/III). This second filter was not reported in the previous study investigating tree shrew V1 laminar RF transformation (Van Hooser et al., 2013),so this discrepancy may due to differences in the method of analysis (normalized vs. non-normalized) or differences in the sample size (e.g., the relatively small sample in layer IV in their study).

Red light rearing effect

The tree shrew is an ideal model to test the effect of unbalanced competition between the color-opponent channel and luminance channel. Tree shrews have a cone 
dominant retina with two type of cones (short wave sensitive, SWS, and long wave sensitive, LWS). Deep red light rearing after birth will deprive activation for SWS cones while stimulating LWS cones normally. Since like monkey and human, SWS cones also appearto contribute little to the luminance channel in this species, the red light rearing paradigm will create a competitive advantage for the luminance channel over the color-opponent channel, which has been shown to lead to an enhanced high temporal frequency response in retinal ganglion cells ( $\mathrm{Lu} \&$ Petry, 2002), supragrannular cortical cells(Van Hooser, Johnson \& Petry, 2014) as well as at the behavioral level (Callahan \& Petry, 1995). One unexpected result of the current study was that no statistically significant difference was observed in the averaged response to higher temporal frequencies between layers II/III neurons in normally-reared tree shrews and in red-light-reared tree shrews, which would have been expected from the imaging results of Van Hooser et al. (2014). This is most likely because the sample size of layer II/III neurons was relatively small in the current study, coupled with the fact that the variance between cells is large for higher frequency responses (since there are both low-pass and band-pass cells in layer II/III, their response differs a lot in higher frequency). There appeared to be an enhancement in low frequency $(1 \mathrm{~Hz})$ response in layer II/III, as expected from the imaging study (Van Hooser et al., 2014), in our data sample that was likely caused by an increased proportion of cells with low-pass high cutoff temporal tuning curves. This observed change in tuning type composition is also in accordance with previous finding that the SWS cone isolation stimuli driven response fell off quickly at higher temporal frequencies $(>8 \mathrm{~Hz}$, thus 
have a low-pass low cutoff shape), while LWS cone isolation stimuli can drive neuron responses well at higher temporal frequencies (up to $30 \mathrm{~Hz}$ ), and thus have a low-pass high cutoff shape (Johnson, Van Hooser \& Fitzpatrick, 2010). If the unbalanced spectral rearing caused competition that made the LWS cone inputs dominant in layer II/III, cells with the low-pass high-cutoff type tuning curves will become more common. It is worth pointing out that the same mechanism may also possibly explain both low-frequency and high-frequency changes observed in the imaging study Van Hooser et al., 2014), because generally all tuning types have fairly strong responses at 3-10 Hz, and the increased proportion of broad tuning types in layer II/III will have biggest effect on low and high end of temporal frequency spectrum. In the current study we did not find a statistically significant difference at any frequency tested in layer IV neurons between normally-reared and RLR groups even we had sufficient sample size. Since layer II/III neurons are considered downstream to layer IV within $\mathrm{V} 1$, this finding suggests that the changes in frequency response of superficial layers after red light rearing was probably not inherited from cortical feed-forward inputs, but more possibly from direct inputs of dLGN layer 3, which is the only layer in tree shrew dLGN that projects mainly to superficial layers (e.g., Usrey, Muly \& Fitzpatrick, 1992) as well as responding to SWS cone isolation stimuli (Johnson et al., 2010).

Another interesting observation in current study was that red light rearing appeared to change layer IV cells' stimulus preference, making them more responsive 
to flashes and/or less responsive to gratings. In normal reared animals, especially in layer IV and V/VI, there appeared to be separate populations of cells that preferred flash or grating stimuli, while in red light rearing group, no clear grating-preferring cell population was found. The source of multiple peaks in grating/flash histogram and the mechanism of distribution change after red light rearing are not clear. The clusters in grating/flash histogram were found not correspond to simple/complex cell dichotomy, nor to high/low orientation selectivity populations, nor to RF categorization we had in current study. One possible explanation is that the multimodal distribution was contributed by cell populations defined by combinations of properties, thus harder to identify, or it may be contributed by intra-cortical interactions that can hardly be captured in first order STRFs. Lastly, we found that after red rearing, the proportion of complex cells increased, and Type II RFs also had an increasing trend. This change may be explained by an axon elaboration mechanism (Butz, Worgotter, \& Ooyen, 2009; Trachtenberg \& Stryker, 2001) caused by unbalanced excitation and inhibition (Maffei, Neson \& Turrigiano, 2004) as a result of RLR. In the tree shrew, layer II/III cells have a relatively strong SWS cone input, so the red light rearing will dramatically decrease the excitatory inputs to cells with strong SWS cone inputs, and as a result, they may be connected with multiple neighboring or even far away cells with horizontal connections, thus possibly expanding the RF size of interconnected cells.

Conclusion and Future directions 
This study revealed a striking diversity of RF structures in tree shrew primary visual cortex (V1). By comparing our results to carnivores and primates, it was revealed that in terms of V1 RF structures and mechanism, carnivores are more similar to primates than to tree shrews (Ringach, 2002). Our results support the idea that the functional organization and mechanism of properties emergence cannot be simply ascribed to the evolutionary ancestral relationship between mammals, factors like localization of eyes, or what aspect of vision is more important for the lifestyle of animal should also taken into consideration (Scholl, Tan, Corey, \& Priebe, 2013). For example, perception of depth is possibly very important for the survival of animals with both eyes facing front, previous research had shown that the phase difference is very important for depth coding in V1 (Anzai, Ohzawa, \& Freeman, 1999), it provide a possible explanation why the RFs with separate "on" and "off" regions (or "on" and "off" phases) are very common in cat and primate V1. In current study, the constant fast moving living style may also explain why tree shrew V1 cells have short reversal intervals between "on" and "off" in X-T maps, and pretty high high-cutoff frequency for temporal frequency. Since the linear model that had been previously demonstrated as successful for predicting the orientation preference and the F1/F0 ratio in carnivores and primates V1 failed to do so when applied to tree shrew cortical neurons, other hypothesis-based models employing intra-cortical interactions should be tested for use in modeling tree shrew visual cortical function. Additionally, the effect of red light rearing on temporal frequency tuning should be further tested using electrophysiology techniques in tree shrew V1, as well as in dLGN, with the goal of 
obtaining a larger sample to discriminate contribution of different mechanisms. 


\section{REFERENCES}

Adelson, E. H., \& Bergen, J. R. (1985). Spatiotemporal energy models for the perception of motion. JOSA A, 2 (2), 284-299.

Adorján, P., Levitt, J., Lund, J., \& Obermayer, K. (1999). A model for the intracortical origin of orientation preference and tuning in macaque striate cortex. Visual neuroscience, 16 (02), 303-318.

Agarwala, A.G. \& Petre, H.M. (1991, Apr.). Patterns of cytochrome oxidase activity in the geniculostriate pathway of red-light-reared tree shrews.Poster session presented at the meeting of Association for Research in Vision and Ophthalmology (ARVO), Sarasota, FL.

Ahnelt, P. K., \& Kolb, H. (2000). The mammalian photoreceptor mosaic-adaptive design. Progress in retinal and eye research, 19 (6), 711-777.

Albright, T. D. (1984). Direction and orientation selectivity of neurons in visual area MT of the macaque. J Neurophysiol, 52 (6), 1106-1130.

Alonso, J.-M., Usrey, W. M., \& Reid, R. C. (2001). Rules of connectivity between geniculate cells and simple cells in cat primary visual cortex. The Journal of Neuroscience, 21 (11), 4002-4015.

An, X., Gong, H., McLoughlin, N., Yang, Y., \& Wang, W. (2014). The Mechanism for Processing Random-Dot Motion at Various Speeds in Early Visual Cortices. PloS one, 9 (3), e93115.

Anzai, A., Ohzawa I,. Freeman R.D., (1999). Neural mechanisms for encoding binocular disparity: receptive field position versus phase. J Neurophysiol. 82(2):874-90

Baker, C. L. (2001). Linear filtering and nonlinear interactions in direction-selective visual cortex neurons: a noise correlation analysis. Visual neuroscience, 18 (03), 465-485.

Barlow, H. B. (1953). Summation and inhibition in the frog's retina. The Journal of Physiology, 119 (1), 69-88.

Blasdel, G.G. (1992). Orientation selectivity, preference, and continuity in monkey 
striate cortex. J Neuroscie. 12(8):3139-61.

Bonhoeffer T., Grinvald A. (1991). Io-orientation domains in cat visual cortex are arranged in pinwheel-like patterns. Nautre. 353(6343):429-31

Boothe, R., Dobson, V. \& Teller,D.Y. (1985). Postnatal development in vision in human and nonhuman primates. Annu. Rev. Neurosci., 8: 495-545.

Bosking, W. H., Zhang, Y., Schofield, B., \& Fitzpatrick, D. (1997). Orientation selectivity and the arrangement of horizontal connections in tree shrew striate cortex. The Journal of Neuroscience, 17 (6), 2112-2127.

Bowling, D. B., and C. R. Michael (1980). Projection patterns of single physiologically characterized optic tract fibres in cat, Nature, 286:899-902.

Boyd, J. D., \& Matsubara, J. A. (1996). Laminar and columnar patterns of geniculocortical projections in the cat: relationship to cytochrome oxidase. Journal of Comparative Neurology, 365 (4), 659-682.

Brenner, E., Schelvis, J. and Nuboer, J.FW. (1985) Early colour deprivation in a monkey (Macaca fascicularis). Vision Res., 25: 1337-1339.

Butz M., Worgotter F., van Ooyen A. (2009). Activity-dependent structureal plasticity. Brain Res Rev, 60(2): 287-305.

Callahan, T.,\& Petry H. (1995). Temporal contrast sensitivity functions of normal and red-light-reared tree shrews.Poster session presented at the meeting of Association for Research in Vision and Ophthalmology (ARVO), Fort Lauderdale, FL.

Callahan, T. L., \& Petry, H. M. (2000). Psychophysical measurement of temporal modulation sensitivity in the tree shrew (Tupaia belangeri). Vision research, 40 (4), 455-458.

Cao, Q.-L., Murphy, H. A., \& Petry, H. M. (1999). Localization of nitric oxide synthase in the tree shrew retina. Visual neuroscience, 16(03), 399-409.

Casagrande, V. A., \& Kaas, J. H. (1994). The afferent, intrinsic, and efferent connections of primary visual cortex in primates Primary visual cortex in primates (pp. 201-259): Springer.

Casagrande, V., \& Harting, J. (1975). Transneuronal transport of tritiated fucose and proline in the visual pathways of tree shrew (Tupaia glis). Brain research, 96 (2), 367-372. 
Chisum, H. J., Mooser, F., \& Fitzpatrick, D. (2003). Emergent properties of layer 2/3 neurons reflect the collinear arrangement of horizontal connections in tree shrew visual cortex. The Journal of Neuroscience, 23 (7), 2947-2960.

Chung, S., \& Ferster, D. (1998). Strength and orientation tuning of the thalamic input to simple cells revealed by electrically evoked cortical suppression. Neuron, 20 (6), 1177-1189.

Cleland, B., Dubin, M., \& Levick, W. (1971). Sustained and transient neurones in the cat's retina and lateral geniculate nucleus. The Journal of Physiology, 217 (2), 473-496.

Conley, M., Fitzpatrick, D., \& Diamond, I. T. (1984). The laminar organization of the lateral geniculate body and the striate cortex in the tree shrew (Tupaia glis). The Journal of Neuroscience, 4 (1), 171-197.

Conway, B. R., \& Livingstone, M. S. (2003). Space-time maps and two-bar interactions of different classes of direction-selective cells in macaque V-1. Journal of neurophysiology, 89 (5), 2726-2742.

Dean, A., \& Tolhurst, D. (1983). On the distinctness of simple and complex cells in the visual cortex of the cat. The Journal of Physiology, 344 (1), 305-325.

de Lange Dzn, H. (1954). Relationship between critical flicker-frequency and a set of low-frequency characteristics of the eye. JOSA, 44 (5), 380-388.

DeAngelis G.C., Ohzawa I., Freeman R.D., (1993). Spatiotemporal organization of simple-cell receptive fields in the cat's striate cortex. I. General characteristics an postnatal development. J Neurophysiol 68(4): 1091-117.

DeAngelis G.C., Ohzawa I., Freeman R.D., (1993). Spatiotemporal organization of simple-cell receptive fields in the cat's striate cortex. II. Linearity of temporal and spatial summation. J Neurophysiol 69(4): 1118-35.

DeAngelis G.C., Ohzawa I., Freeman R.D., (1995). Receptive-field dynamics in the central visual pathways. Trends Neurosci. 18(10): 451-8

Derrington, A., \& Lennie, P. (1984). Spatial and temporal contrast sensitivities of neurones in lateral geniculate nucleus of macaque. The Journal of Physiology, 357 (1), 219-240.

Dongen, P. v., Laak, H. t., Thijssen, J., \& Vendrik, A. (1976). Functional classification of cells in the optic tract of a tree shrew (Tupaia chinensis). Experimental Brain Research, 24 (4), 441-446.

Douglas, R. J., \& Martin, K. A. (2004). Neuronal circuits of the neocortex. Annu. Rev. 
Neurosci., 27, 419-451.

Eisner, A. \& MacLeod, D.I.A. (1980). Blue-sensitive cones do not contribute to luminance. J.Opt.Soc.Am., 70:121-123

Enroth-Cugell, C., \& Robson, J. G. (1966). The contrast sensitivity of retinal ganglion cells of the cat. The Journal of Physiology, 187 (3), 517-552.

Ferster, D. (1988). Spatially opponent excitation and inhibition in simple cells of the cat visual cortex. The Journal of Neuroscience, 8 (4), 1172-1180.

Ferster, D., Chung, S., \& Wheat, H. (1996). Orientation selectivity of thalamic input to simple cells of cat visual cortex. Nature, 380 (6571), 249-252.

Ferster, D., \& Miller, K. D. (2000). Neural mechanisms of orientation selectivity in the visual cortex. Annual review of neuroscience, 23 (1), 441-471.

Gardner, J. L., Anzai, A., Ohzawa, I., \& Freeman, R. D. (1999). Linear and nonlinear contributions to orientation tuning of simple cells in the cat's striate cortex. Vis Neurosci, 16 (6), 1115-1121.

Geisler, W. S., Albrecht, D. G., Crane, A. M., \& Stern, L. (2001). Motion direction signals in the primary visual cortex of cat and monkey. Visual neuroscience, 18(04), 501-516.

Gilbert, C.D. (1977). Laminar differences in receptive field properties of cells in cat primary visual cortex. J Physiol., 268(2): 391-421.

Gilbert, C. D. (1983). Microcircuitry of the visual cortex. Annual review of neuroscience, 6 (1), 217-247.

Gilbert, C. D., and J. P. Kelly, 1975. The projections of cells in different layers of the cat's visual cortex, J. Comp. Neurol., 163:81-106

Glenn Northcutt, R., \& Kaas, J. H. (1995). The emergence and evolution of mammalian neocortex. Trends in neurosciences, 18 (9), 373-379.

Harting, J., Diamond, I., \& Hall, W. (1973). Anterograde degeneration study of the cortical projections of the lateral geniculate and pulvinar nuclei in the tree shrew (Tupaia glis). Journal of Comparative Neurology, 150 (4), 393-439.

Hawken, M., Shapley, R., \& Grosof, D. (1996). Temporal-frequency selectivity in monkey visual cortex. Visual neuroscience, 13 (03), 477-492.

Hendry, S. H., \& Reid, R. C. (2000). The koniocellular pathway in primate vision. Annual review of neuroscience, 23 (1), 127-153. 
Hirsch, J. A., \& Martinez, L. M. (2006a). Circuits that build visual cortical receptive fields. Trends in neurosciences, 29 (1), 30-39.

Hirsch, J. A., \& Martinez, L. M. (2006b). Laminar processing in the visual cortical column. Current opinion in neurobiology, 16 (4), 377-384.

Hirsch, J. A., Martinez, L. M., Pillai, C., Alonso, J.-M., Wang, Q., \& Sommer, F. T. (2003). Functionally distinct inhibitory neurons at the first stage of visual cortical processing. Nature neuroscience, 6 (12), 1300-1308.

Holdefer, R. N., \& Norton, T. T. (1995). Laminar organization of receptive field properties in the dorsal lateral geniculate nucleus of the tree shrew (Tupaiaglis belangeri). Journal of Comparative Neurology, 358 (3), 401-413.

Hubel, D. H. (1975). An autoradiographic study of the retino-cortical projections in the tree shrew (Tupaia glis). Brain research, 96 (1), 41-50.

Hubel, D. H., \& Wiesel, T. N. (1959). Receptive fields of single neurones in the cat's striate cortex. The Journal of Physiology, 148 (3), 574.

Hubel, D. H., \& Wiesel, T. N. (1962). Receptive fields, binocular interaction and functional architecture in the cat's visual cortex. The Journal of Physiology, 160(1), 106.

Hubel, D. H., \& Wiesel, T. N. (1968). Receptive fields and functional architecture of monkey striate cortex. The Journal of Physiology, 195 (1), 215-243.

Hubel, D.H., Wiesel, t.N. and LeVay, S. (1977) Plasticity of ocular dominance columns in monkey striate cortex. Phil. Trans. R. Soc. Lond. B., 278:377-409

Hoffmann KP, Stone J, Sherman SM. (1972). Relay of receptive-field properties in dorsal lateral geniculate nucleus of the cat. J Neurophysiol. ,35(4):518-531

Humphrey, A. L., Skeen, L. C., \& Norton, T. T. (1980). Topographic organization of the orientation column system in the striate cortex of the tree shrew (Tupaia glis). II. Deoxyglucose mapping. Journal of Comparative Neurology, 192 (3), 549-566.

Irvin, G. E., Casagrande, V. A., \& Norton, T. T. (1993). Center/surround relationships of magnocellular, parvocellular, and koniocellular relay cells in primate lateral geniculate nucleus. Visual neuroscience, 10 (02), 363-373.

Jacobs, G. H., \& Neitz, J. (1986). Spectral mechanisms and color vision in the tree shrew ( Tupaia belangeri). Vision research, 26 (2), 291-298.

Jain, N., Preuss, T. M., \& Kaas, J. H. (1994). Subdivisions of the visual system 
labeled with the Cat-301 antibody in tree shrews. Visual neuroscience, 11 (04), 731-741.

Jancke, D. (2000). Orientation formed by a spot's trajectory: A two-dimensional population approach in primary visual cortex. Journal of Neuroscience, 20 (14), U13-U18.

Johnson, E. N., Van Hooser, S. D., \& Fitzpatrick, D. (2010). The representation of S-cone signals in primary visual cortex. The Journal of Neuroscience, 30(31), 10337-10350.

Jones, J. P., \& Palmer, L. A. (1987). The two-dimensional spatial structure of simple receptive fields in cat striate cortex. Journal of Neurophysiology,58 (6), 1187-211.

Kaufmann PG, Somjen GG. 1979. Receptive fi elds of neurons in areas 17 and 18 of tree shrews ( Tupaia glis ). Brain Res Bull. 4:319-325.

Kagan, I., Gur, M., \& Snodderly, D. M. (2002). Spatial organization of receptive fields of V1 neurons of alert monkeys: comparison with responses to gratings. Journal of neurophysiology, 88 (5), 2557-2574.

Kaplan, E., Lee, B. B., \& Shapley, R. M. (1990). New views of primate retinal function. Progress in retinal research, 9, 273-336.

Kaas, J. H., Hall, W., Killackey, H., \& Diamond, I. (1972). Visual cortex of the tree shrew (Tupaia glis): Architectonic subdivisions and representations of the visual field. Brain research, 42 (2), 491-496.

Kaas, J. H., \& Preuss, T. M. (1993). Archontan affinities as reflected in the visual system. Mammal phyologeny: placentals. New York: Springer-Verlag, $115-128$

Kelly, J.P., Williams, C.D. \& Petry, H.M. (1991,Apr.). Spectral sensitivity of normal and red-light-reared tree shrews.Poster session presented at the meeting of Association for Research in Vision and Ophthalmology (ARVO), Fort Lauderdale, FL.

King-Smith, P.E., \& Cardern D. (1976). Luminance and opponent-color contributions to visual detection and adaptation and to temporal and spatial integration. $J$ Opt Soc Am, 66(7):709-17.

Lee, B. B. (1996). Receptive field structure in the primate retina. Vision research, 36 (5), 631-644.

Leventhal, A. G., R. W. Rodieck, and B. Dreher. (1981). Retinal ganglion cell classes 
in the Old World monkey: morphology and central projections, Science, 213:1139-1142.

Liu S., Liu Y.J, Li B. (2007). Spatiotemporal structure of complex cell receptive fields and influence of GABAergic inhibitoin. Neuroreport, 18(15): 1577-81.

Livingstone, M., \& Hubel, D. (1988). Segregation of form, color, movement, and depth: anatomy, physiology, and perception. Science, 240 (4853), 740-749.

Lu, H. \& Petry, H.M. (2002, May). Long-term changes in the temporal modulation sensitivity of retinal ganglion cells in tree shrews reared in red light. Poster session presented at the meeting of Association for Research in Vision and Ophthalmology (ARVO), Fort Lauderdale, FL.

Maffei, A., Nelson S.B., Turrigiano, G.G. (2004). Selective reconfiguration of layer 4 visual cortical circuitry by visual deprevation. Nat Neurosci. 7(12), 1353-9.

Martin, K. A. (1994). A brief history of the "feature detector". Cerebral cortex, 4(1), $1-7$.

Martinez, L. M., Alonso, J.-M., Reid, R. C., \& Hirsch, J. A. (2002). Laminar processing of stimulus orientation in cat visual cortex. The Journal of Physiology, 540 (1), 321-333.

Martinez, L. M., Wang, Q., Reid, R. C., Pillai, C., Alonso, J.-M., Sommer, F. T., \& Hirsch, J. A. (2005). Receptive field structure varies with layer in the primary visual cortex. Nature neuroscience, 8 (3), 372-379.

Mata ML, Ringach DL. (2005). Spatial overlap of ON and OFF subregions and its relation to response modulation ratio in macaque primary visual cortex. $J$ Neurophysiol. 93:919-928.

McLean, J., \& Palmer, L. A. (1989). Contribution of linear spatiotemporal receptive field structure to velocity selectivity of simple cells in area 17 of cat. Vision research, 29 (6), 675-679.

McLean, J., Raab, S., \& Palmer, L. (1994). Contribution of linear mechanisms to the specification of local motion by simple cells in areas 17 and 18 of the cat. Visual neuroscience, 11 (02), 271-294.

Merigan, W. H., \& Maunsell, J. H. (1993). How parallel are the primate visual pathways? Annual review of neuroscience, 16 (1), 369-402.

Monier, C., Chavane, F., Baudot, P., Graham, L. J., \& Frégnac, Y. (2003). Orientation and direction selectivity of synaptic inputs in visual cortical neurons: a diversity of combinations produces spike tuning. Neuron, 37 (4), 663-680. 
Mooser, F., Bosking, W. H., \& Fitzpatrick, D. (2004). A morphological basis for orientation tuning in primary visual cortex. Nature neuroscience, 7 (8), $872-879$.

Müller, B., \& Peichl, L. (1989). Topography of cones and rods in the tree shrew retina. Journal of Comparative Neurology, 282 (4), 581-594.

Murphy, H., Petry H. (1995). NADPH-Diaphorase labeling of SWS cones in adult tree shrew retina is compromised by post-natal red light rearing. Poster session presented at the meeting of Association for Research in Vision and Ophthalmology (ARVO), Fort Lauderdale, FL.

Norton, T. T., \& McBrien, N. A. (1992). Normal development of refractive state and ocular component dimensions in the tree shrew (Tupaia belangeri). Vision research, 32 (5), 833-842.

Norton, T. T., Rager, G., \& Kretz, R. (1985). ON and OFF regions in layer IV of striate cortex. Brain research, 327 (1), 319-323.

Párraga, C., Troscianko, T., \& Tolhurst, D. (2005). The effects of amplitude-spectrum statistics on foveal and peripheral discrimination of changes in natural images, and a multi-resolution model. Vision research, 45 (25), 3145-3168.

Perry, V. H., R. Oehler, and A. Cowey. (1984). Retinal ganglion cells that project to the dorsal lateral geniculate nucleus in the macaque monkey, Neurosci., 12:1101-1123.

Petry, H. M. (1993). Long-term changes in visual mechanisms following differential stimulation of color and luminance channels during development. Progress in brain research, 95, 235-250.

Petry, H. M., Erichsen, J. T., \& Szél, Á. (1993). Immunocytochemical identification of photoreceptor populations in the tree shrew retina. Brain research, 616 (1), 344-350.

Petry, H. M., \& Harosi, F. I. (1990). Visual pigments of the tree shrew (Tupaia belangeri) and greater galago (Galago crassicaudatus): A microspectrophotometric investigation. Vision research, 30 (6), 839-851.

Petry, H.H. and Kelly, J.P. (1991) Psychophysical measurement of spectral sensitivity and color vision in red-light-reared tree shrews (Tupaia belangeri). Vision Res., 31: 1749-1757.

Petry, H.M. \& Lu, H. (2001, Dec.).Improved temporal vision after a color deprivation paradigm: correlates in retinal ganglion cells. Poster session presented at the 
meeting of Vison Sciences Society (VSS), Sarasota, FL.

Petry, H.M., Williams, C.D., Kelly, J.P. (1992, May). Enhanced luminance channel sensitivity in red-light-reared tree shrews: the result of a competitive advantage during development.Poster session presented at the meeting of Association for Research in Vision and Ophthalmology (ARVO), Fort Lauderdale, FL.

Priebe, N. J., \& Ferster, D. (2005). Direction selectivity of excitation and inhibition in simple cells of the cat primary visual cortex. Neuron, 45 (1), 133-145.

Priebe, N. J., \& Ferster, D. (2012). Mechanisms of neuronal computation in mammalian visual cortex. Neuron, 75 (2), 194-208.

Priebe, N. J., Mechler, F., Carandini, M., \& Ferster, D. (2004). The contribution of spike threshold to the dichotomy of cortical simple and complex cells. Nature neuroscience, 7 (10), 1113-1122.

Reid, R. C., \& Alonso, J.-M. (1995). Specificity of monosynaptic connections from thalamus to visual cortex. Nature, 378 (6554), 281-283.

Reid, R. C., Soodak, R., \& Shapley, R. (1988). Directional selectivity and the spatiotemporal structure of the receptive fields of simple cells in cat striate cortex. Am Physiological Soc.

Ringach, D. L. (2004). Mapping receptive fields in primary visual cortex. The Journal of Physiology, 558 (3), 717-728.

Rust, N. C., Schwartz, O., Movshon, J. A., \& Simoncelli, E. P. (2005). Spatiotemporal elements of macaque v1 receptive fields. Neuron, 46 (6), 945-956.

Schiller, P. H., \& Malpeli, J. G., (1978). Functional specificity of lateral geniculate nucleus laminae of the rhesus monkey. J Neurophysiol, 41(3), 788-97

Sedigh-Sarvestani, M., Fernandez-Lamo, I., Jaegle, A., \& Taylor, M. M. (2014). Second Order Receptive Field Properties of Simple and Complex Cells Support a New Standard Model of Thalamocortical Circuitry in V1. The Journal of Neuroscience, 34 (34), 11177-11179.

Sereno, A., \& Maunsell, J. (1998). Shape selectivity in primate lateral intraparietal cortex. Nature, 395 (6701), 500-503.

Sesma, M., Casagrande, V., \& Kaas, J. (1984). Cortical connections of area 17 in tree shrews. Journal of Comparative Neurology, 230 (3), 337-351.

Shapley, R., Hawken, M., \& Ringach, D. L. (2003). Dynamics of orientation 
selectivity in the primary visual cortex and the importance of cortical inhibition. Neuron, 38 (5), 689-699.

Sherman, S.M., \& Guillery R.W.(1996). The functional organization of thalamocortical relays, J. Neurophysiol., 76:1367-1395.

Sherman, S.M, \& Spear, P.D. (1982). Organization of visual pathways in normal an visually deprived cats. Physiol. rev., 62: 738-855.

Sun, W., \& Dan, Y. (2009). Layer-specific network oscillation and spatiotemporal receptive field in the visual cortex. Proceedings of the National Academy of Sciences, 106 (42), 17986-17991.

Tanaka, K. (1983). Cross-correlation analysis of geniculostriate neuronal relationships in cats. J Neurophysiol, 49 (6), 1303-1318.

Tanaka, K. (1996). Inferotemporal cortex and object vision. Annual review of neuroscience, 19 (1), 109-139.

Thijssen, J., van Dongen, P., \& ter Laak, H. (1976). Maintained activity of cells in the tree shrew's optic tract. Experimental Brain Research, 25 (3), 279-290.

Tigges, J., Brooks, B. A., \& Klee, M. (1967). ERG recordings of a primate pure cone retina (Tupaia glis). Vision research, 7 (7), 553-563.

Touryan, J., Felsen, G., \& Dan, Y. (2005). Spatial structure of complex cell receptive fields measured with natural images. Neuron, 45 (5), 781-791.

Trachtenberg J.T., Stryker M.P. (2001). Rapid anatomical plasticity of horizontal connections in the developing visal cortex. J Neuroscie. 21(10): 3467-82.

Usrey, W. M., Alonso, J.-M., \& Reid, R. C. (2000). Synaptic interactions between thalamic inputs to simple cells in cat visual cortex. The Journal of Neuroscience, 20 (14), 5461-5467.

Usrey, W. M., Muly, E. C., \& Fitzpatrick, D. (1992). Lateral geniculate projections to the superficial layers of visual cortex in the tree shrew. Journal of Comparative Neurology, 319(1), 159-171.

Van Hooser, S. D., Roy, A., Rhodes, H. J., Culp, J. H., \& Fitzpatrick, D. (2013). Transformation of receptive field properties from lateral geniculate nucleus to superficial V1 in the tree shrew. The Journal of Neuroscience, 33 (28), 11494-11505.

Van Hooser, S. D., Johnson, E., Petry, H.M. (2014,Nov.). Early color deprivation enhance motion sensitivity in mature primary visual cortex (V1).Poster session 
presented at the meeting of Society for Neuroscience (SfN), Washington D.C.

Veit, J., Bhattacharyya, A., Kretz, R., \& Rainer, G. (2013). On the relation between receptive field structure and stimulus selectivity in the tree shrew primary visual cortex. Cerebral cortex, bht133.

Wiesel Y.N., \& Hubel D.H. (1965). Comparision of the effect of unilateral and bilateral eye cosure on cortical unit responses in kittens. Journal of Nueophysiology, 28(6), 1029-1040.

Yeh, C.-I., Xing, D., Williams, P. E., \& Shapley, R. M. (2009). Stimulus ensemble and cortical layer determine V1 spatial receptive fields. Proceedings of the National Academy of Sciences, 106 (34), 14652-14657. 


\author{
CURRICULUM VITAE \\ Wenhao Dang \\ wenhao.dang@louisville.edu \\ Department of Psychological and Brain Sciences| \\ University of Louisville| Louisville, KY 40292
}

\title{
EDUCATION
}

PhD candidate, Experimental Psychology (University of Louisville).......Expected Aug. 2015

Dissertation: Temporal information processing across primary visual cortical layers in normal and red light reared tree shrews.

M.S., Experimental Psychology (University of Louisville)......................................Sep.2012

B.S, Molecular Biology (China Agricultural University, Beijing, China).

Oct. 2009

\section{HONORS AND FELLOWSHIPS}

University Fellowship (School of Interdisciplinary \& Graduate Studies, University of Louisville), 2010-2011 and 2011-2012.

Graduate Student Research and Creative Activities Grant(College of Arts \& Sciences, University of Louisville), 2014.

Dissertation Completion Grant (School of Interdisciplinary \& Graduate Studies, University of Louisville), 2015.

\section{RESEARCH EXPERIENCE}

University of Louisville, Louisville, KY

Graduate researcher; Mentor: Dr. Heywood M. Petry. Aug.2010-Present

Single-unit electrophysiological studies of receptive field properties of neurons in the visual thalamus (pulvinar) and visual cortex of tree shrews (Tupaia), a close relative to primates.

- Used in-vivo extracellular recording techniques to study the effects of early visual experience on tuning properties and spatial-temporal receptive fields of V1 neurons.

- Helped design and implement apparatus for recording from the visual thalamus in alert animals.

- Wrote MATLAB scripts for generating complex visual stimuli and for the acquisition and analysis of neuron responses.

- Reconstructed microelectrode tracks to identify locations of recorded neurons 


\section{Neuroscience Research Institute of Peking University Health Science Center,}

Beijing, China

Undergraduate researcher; Advisor: Dr. Guogang Xing July2008-May 2009

Contribution of NR2B subunit-containing NMDA receptors to the development of neuropathic pain.

- Used immuno-histochemistry to investigate the spinal cord NR2B subunit expression pattern in neuropathic pain model.

\section{RESEARCH TECHNIQUE PROFICIENCIES}

Small animal surgery; Sterile cranial surgery; Single-unit electrophysiology; Histology; Microscopy; Programming (MATLAB, C language); Quantitative analysis (linear model used in dissertation work, Fourier analysis, convolution; took online courses on Coursera.org, and got certificates on computational neuroscience andmachine learning); Animal husbandry and breeding; Some experience with in-vivo and in-vitro optogenetics.

\section{PUBLICATIONS}

Geng S.J, Liao F.F., Dang W.H., Ding X., Liu X.D., Cai J, Han J.S., Wan Y., Xing G.G. (2010). Contribution of the spinal cord BDNF to the development of neuropathic pain by activation of the NR2B-containing NMDA receptors in rats with spinal nerve ligation. Experimental Neurology.222(2), 256-66.

Familtsev D., Quiggins R., Masterson S.P., Dang W., Slusarczyk A.S.,PetryH.M. and Bickford M.E.(Submitted, revision in progress).The ultrastructure of geniculocortical synaptic connections in the tree shrew striate cortex.

\section{CONFERENCE PRESENTATIONS (National/International)}

Dang W., Masterson S.P., Day-Brown J.D., MaireP.S., Bickford M.E., Petry H.M. (2012). Receptive field characteristics of visually-responsive neurons in the tree shrew pulvinar nucleus. Poster presentation delivered at the Society for Neuroscience meeting, New Orleans, LA, October 2012.

Dang W., Maire P.S., Petry H.M. (2014).Response properties of individual visual cortex neurons to different types of commonly used motion stimuli. Poster presentation delivered at the Society for Neuroscience meeting, Washington,D.C., November 2014.

Masterson S., Akers B., Dang W., Zhou N., Govindaiah G., Guido W., Bickford M.E., (2014). Ultrastructural and optogenetic dissection of V1 corticotectal synapses in the mouse.Poster presentation delivered at the Society for Neuroscience meeting, 
Washington, DC, November 2014.

Dang W., Maire P.S., Petry H.M. (2015).Receptive field properties of neurons in primary visual cortex (V1) of normal and red light reared tree shrews.Poster presentation to be delivered at the Society for Neuroscience meeting, ChicagoIL, October 2015.

\section{CONFERENCE PRESENTATIONS (LOCAL)}

Maire PS, Dang W, Masterson SP, Bickford ME, Petry HM. Visual properties of pulvinar neurons in the tree shrew brain. Presented at the University of Louisville Undergraduate Research Symposium, August 2012.

DangWH, Masterson SP, Day-Brown JD, Bickford ME, MairePS, Petry HM. (2013) Receptive field characteristics of visually-responsive neurons in the tree shrew pulvinar nucleus. Presented at annual meeting of the Louisville Chapter of the Society for Neuroscience, April, 2013

DangWH, MairePS, Petry HM. (2014) Coding of visual motion in tree shrew striate cortex.Presented at annual meeting of the Louisville Chapter of the Society for Neuroscience, April, 2014

\section{TEACHING EXPERIENCE}

Graduate teaching assistant for PSYC 201 "Introduction to Psychology" Spring 2015 (Instructor: Dr. Edna Ross, Dr. Rich Lewine, Dr. Paul Demarco)

Duties: Proctor exams, calculate and upload scores to the BlackBoard web site.

Graduate teaching assistant for PSYC 321"Introduction to Psychology of Learning"; Fall 2013; Spring 2014; Fall 2014 (Instructor: Dr. Melinda Leonard);

Duties: Teach students how to use a lab rat behavior simulation software -Sniffy, and explain simulated behaviors using principles they learned in lectures.

Graduate teaching assistant for PSYC 302 "Experimental Psychology"

Spring 2013 (Instructor: Dr. Marci DeCaro);

Duties: Instruct students in APA format writing

Graduate teaching assistant for PSYC 201 "Introduction to Psychology"

Fall 2012 (Instructor: Dr. Melinda Leonard)

Duties: Instruct students in APA format writing. 